\title{
Effects of desiccation stress on adult female longevity in Aedes aegypti and Ae. albopictus (Diptera: Culicidae): results of a systematic review and pooled survival analysis
}

Chris A. Schmidt ${ }^{1,2^{*}}$, Genevieve Comeau ${ }^{3}$, Andrew J. Monaghan², Daniel J. Williamson ${ }^{3}$ and Kacey C. Ernst ${ }^{1,3}$

\begin{abstract}
Background: Transmission dynamics of mosquito-borne viruses such as dengue, Zika and chikungunya are affected by the longevity of the adult female mosquito. Environmental conditions influence the survival of adult female Aedes mosquitoes, the primary vectors of these viruses. While the association of temperature with Aedes mortality has been relatively well-explored, the role of humidity is less established. The current study's goals were to compile knowledge of the influence of humidity on adult survival in the important vector species Aedes aegypti and Ae. albopictus, and to quantify this relationship while accounting for the modifying effect of temperature.

Methods: We performed a systematic literature review to identify studies reporting experimental results informing the relationships among temperature, humidity and adult survival in Ae. aegypti and Ae. albopictus. Using a novel simulation approach to harmonize disparate survival data, we conducted pooled survival analyses via stratified and mixed effects Cox regression to estimate temperature-dependent associations between humidity and mortality risk for these species across a broad range of temperatures and vapor pressure deficits.

Results: After screening 1517 articles, 17 studies (one in semi-field and 16 in laboratory settings) met inclusion criteria and collectively reported results for 192 survival experiments. We review and synthesize relevant findings from these studies. Our stratified model estimated a strong temperature-dependent association of humidity with mortality in both species, though associations were not significant for Ae. albopictus in the mixed effects model. Lowest mortality risks were estimated around $27.5^{\circ} \mathrm{C}$ and $21.5^{\circ} \mathrm{C}$ for Ae. aegypti and Ae. albopictus, respectively, and mortality increased non-linearly with decreasing humidity. Aedes aegypti had a survival advantage relative to Ae. albopictus in the stratified model under most conditions, but species differences were not significant in the mixed effects model.

(Continued on next page)
\end{abstract}

\footnotetext{
* Correspondence: cschmidt@email.arizona.edu

${ }^{1}$ Department of Epidemiology and Biostatistics, Mel \& Enid Zuckerman

College of Public Health, University of Arizona, 1295 N. Martin Ave, Tucson,

AZ 85724, USA

${ }^{2}$ National Center for Atmospheric Research, P.O. Box 3000, Boulder, CO

80307, USA

Full list of author information is available at the end of the article
} 
(Continued from previous page)

Conclusions: Humidity is associated with mortality risk in adult female Ae. aegypti in controlled settings. Data are limited at low humidities, temperature extremes, and for Ae. albopictus, and further studies should be conducted to reduce model uncertainty in these contexts. Desiccation is likely an important factor in Aedes population dynamics and viral transmission in arid regions. Models of Aedes-borne virus transmission may be improved by more comprehensively representing humidity effects.

Keywords: Aedes aegypti, Aedes albopictus, Longevity, Survival, Humidity, Vapor pressure, Temperature, Review, Pooled analysis,

\section{Background}

Aedes mosquitoes are vectors of multiple viruses of major public health significance, including dengue (DENV), yellow fever (YFV), chikungunya (CHIKV) and Zika (ZIKV) viruses [1]. Over the past four decades, Aedes (Stegomyia) aegypti (Linnaeus) and Ae. (S.) albopictus (Skuse) have expanded rapidly across the globe [2-4]. Both vectors are now well-established throughout much of the tropics and subtropics. Concurrently, DENV has continued to expand in the Western Hemisphere [5] and to cause a substantial global disease burden [6], CHIKV and ZIKV have emerged as significant threats in the Americas and elsewhere [7, 8], and recent outbreaks of YFV in central Africa and Brazil have increased concerns about its epidemic potential [9]. As continued transmission of Aedes-borne viruses is anticipated, proactive systems are needed to monitor and forecast times and areas of high transmission risk.

Process-based mathematical models of mosquito populations and arboviral transmission have enhanced the ability to forecast disease dynamics and predict impacts from vector control efforts [10-18]. Adult survival rate or longevity is a highly influential component of mosquito population models and vectorial capacity equations given its relationship to average generation time, fecundity and biting rate, and its interaction with viral extrinsic incubation periods ("EIP"; [18-22]). Aedes females newly infected with a viral pathogen must survive long enough for the virus to multiply and reach its salivary glands before the virus can be transmitted to a new host, and longer lifespans beyond the EIP increase the potential number of hosts that may be newly infected [22-24].

Environmental factors strongly influence the life-cycle and vectorial capacity of Ae. aegypti and Ae. albopictus. For example, temperature affects adult longevity, immature development, EIP, and other components of Aedes life history and vectorial capacity [18, 22, 25-32]. The association of temperature with adult survival frequently features in Aedes population and disease models (e.g. $[10,11,14,33])$, and a recent study quantified this relationship to improve model parameterization [34]. Humidity also influences the ecological dynamics and life-cycle of Aedes mosquitoes in numerous ways, as reviewed below in reference to (i) the ecology and seasonality of Aedes and Aedes-transmitted viruses; (ii) desiccation of Aedes; and (iii) Aedes container habitats.

Numerous analyses have found humidity to be directly or indirectly associated with the ecology and seasonality of Aedes and with the incidence of associated viral diseases (e.g. [35-42]). Hales et al. [43], for example, identified annual average vapor pressure (a measure of humidity) as the best climatic predictor of the global distribution of dengue. Some studies have failed to find this relationship, however (e.g. [44]). Aedes abundance and Aedes-transmitted virus incidence show distinct seasonality in many regions globally, and may be indirectly linked to humidity through annual cycles of temperature and precipitation [31]. Seasonal increases in Aedes mosquito abundance and/or dengue incidence are associated with rainfall in Asia [45-48] and the Americas [49-52]. Rainfall is likely a driver of seasonality as it creates aquatic habitat for immature mosquito stages (e.g. $[28,53])$, but is not a prerequisite for Aedes occurrence as water-filled containers are often manually filled throughout the year [54].

Humid conditions coincide with the moist air masses that bring rainfall [55], as warm season rainfall is driven by convective heating and occasional mechanical uplift, both very localized phenomena, but precipitation requires the generally widespread advection of moist unstable air [56]. For example, the North American monsoon is characterized by large-scale regional influxes of humidity which may not generate precipitation in a given time and place due to local topography and atmospheric dynamics $[55,57]$, but might be sufficient to moderate desiccation stress and evaporation rates. Conversely, relative humidity may also vary at small scales irrespective of precipitation, for example in relation to land use within urban environments [58] at scales that are likely to be relevant to urban mosquitoes such as $A e$. aegypti. This partial decoupling of humidity and precipitation suggests that rainfall may be an incomplete proxy for humidity in Aedes models. More explicitly and completely quantifying the effects of humidity may improve model simulations of the ecology and seasonality of viral transmission by Aedes. Such improvements may be 
particularly impactful for simulations in understudied arid and semi-arid regions, where seasonal fluctuations of humidity can be substantial (e.g. [57]), and where $30 \%$ of the global population resides [59].

Humidity can impact Aedes mosquito survival directly through desiccation effects on eggs and adults (e.g. [60]), with the rate of water loss in adult mosquitoes increasing with decreasing humidity [61]. Desiccation (extreme drying) affects the volume and osmolarity of hemolymph in the hemocoel of adult insects [62]. Normal water content in adult insects ranges from $40-90 \%$ of wet mass [62], and Aedes mosquitoes can lose up to $40 \%$ of their water content before dying [63]. Process-based models have endeavored to include the desiccation effects of humidity. For example, Lega et al. [64] report that inclusion of humidity into life-cycle models improves model fit to field data, despite their study using a blunt approach, with a one-step increase in adult survival between $72 \%$ and $95 \%$ relative humidity. Similarly, the CIMSiM and Skeeter Buster models [10, 11, 20, 65] use a simple three-step function to define the relationship between humidity and adult survival. However, the absence of a comprehensive review and quantitative model of humidity-associated adult mortality in Aedes has hindered its full incorporation into ecological and epidemiological models [18, 34].

Humidity may also indirectly affect Aedes populations by modulating evaporation rates from water-filled containers in which larvae and pupae develop (e.g. [66-68]). Fluctuations in humidity can have striking effects on evaporation rates. For a given temperature, the evaporation rate of water is about four times larger when relative humidity (RH) is $40 v s 85 \%$. The former value is characteristic of arid cities such as Phoenix, Arizona, while the latter value is common in humid subtropical cities such as Miami, Florida. Additionally, as temperatures incrementally increase, evaporation rates increase non-linearly, meaning that rates are disproportionately larger at hotter temperatures (e.g. $>30{ }^{\circ} \mathrm{C} v s<20{ }^{\circ} \mathrm{C}$ ). Experimental studies have demonstrated that increased larval competition and reduced volume of larval development sites (i.e. via drying) can decrease the size of Aedes females at eclosion [69-71] and that body size likewise influences vectorial capacity [71-73].

In summary, further investigation into the role of humidity in the survival of Aedes mosquitoes and subsequent risk for Aedes-transmitted viruses is motivated by incomplete knowledge of the association of humidity with Aedes ecology and seasonality, the physiological effects of desiccation in adult mosquitoes, and the large fluctuations of evaporation and desiccation that can arise from regularly-observed changes in humidity. The objectives of the current study were to (i) compile knowledge of the influence of humidity on adult survival in Ae. aegypti and Ae. albopictus via a systematic review of published research, and (ii) assimilate this information in a pooled analysis to quantify the relationship between humidity and adult survival while accounting for the modifying effect of temperature. Our approach provides an opportunity to improve Aedes population and disease transmission models by accommodating a non-linear and temperature-dependent relationship between humidity and survival.

\section{Methods}

Reporting follows the PRISMA (Preferred Reporting Items for Systematic Reviews and Meta-Analyses) statement [74].

\section{Literature search}

Studies were identified by searching electronic databases without restrictions on language or publication year. Searches were conducted from 7-13 February 2016 in Web of Science (all databases), PubMed, Google Scholar, WHOLIS, Scopus, LILACS, PAHO, CUMED, and MEDCarib. Spanish translations of key terms were added to searches in the latter four databases. Search strings consisted of thematic terms related to Aedes, humidity, temperature, and longevity, and were structured for each database as necessitated by their specific formats. The full list of search strings is provided in Additional file 1. All results were downloaded and concatenated, except that only the top 200 hits (sorted by relevance) were retained from Google Scholar.

Abstracts of all unique articles were assessed independently by two authors (CS, GC) and retained for further review if they appeared to report results of experimental or observational studies of adult longevity in Ae. aegypti or Ae. albopictus. Database searches were supplemented by three rounds of forward and backward reference searches of candidate articles. Full text was retrieved for all articles considered potentially eligible by at least one reviewer, and was independently reviewed by the same two authors. Disagreements over final study inclusion were resolved by consensus with a third author $(\mathrm{KE})$, and non-English language articles were evaluated with translation support. Articles were eligible for final inclusion in the review if they were formally published, reported original survival data for adult female $A e$. aegypti or Ae. albopictus in laboratory, semi-field or field conditions, and met additional inclusion criteria as follows. Longevity data were required to be reported as raw individual survival times, survival curves, or mean or median longevities, with sample sizes indicated. Studies were required to report results from at least two cohorts exposed to different temperature-humidity regimens. While studies reporting experimental results from only a single temperature and humidity regimen may provide 
useful information about absolute mortality rates, the goal of our study was to estimate temperature and humidity effects on relative mortality, which requires the availability of two or more temperature-humidity regimes in a given study to establish a contrast. Studies were required to report experimental designs in sufficient detail to determine temperature, humidity, and water and nutritional provisioning, which a priori were considered essential influences on longevity, with other conditions kept constant among experiments. Mosquito cohorts were required to be unexposed to chemical treatment or intentional microbial infection (including Wolbachia) and to represent non-transgenic lineages; studies failing these criteria were examined for the presence of control groups that were otherwise eligible.

\section{Data extraction}

A directed acyclic graph (DAG) was developed to explicitly highlight hypothesized relationships among variables and support development of appropriate statistical models (Fig. 1). Key variables were extracted for mosquito cohorts in each study: (i) setting (laboratory, semi-field or field); (ii) species; (iii) total sample size across replicates; (iv) longevity (see below); (v) mean temperature and relative humidity; and (vi) separate variables for water, sugar and blood meal provision. As water, sugar and blood meals were provided using diverse methods and at widely varying frequencies, durations, and qualities, they were simplified to binary presence/absence variables indicating provision at any point after the start of an experiment. Water provisioning was considered present if a sugar solution or blood meal was provided, as these nutrition sources also provide hydration.

In cases where only temperature or humidity ranges were provided, the midpoints were taken to represent mean conditions. To analyze the role of a biologically meaningful measure of desiccation stress, saturation

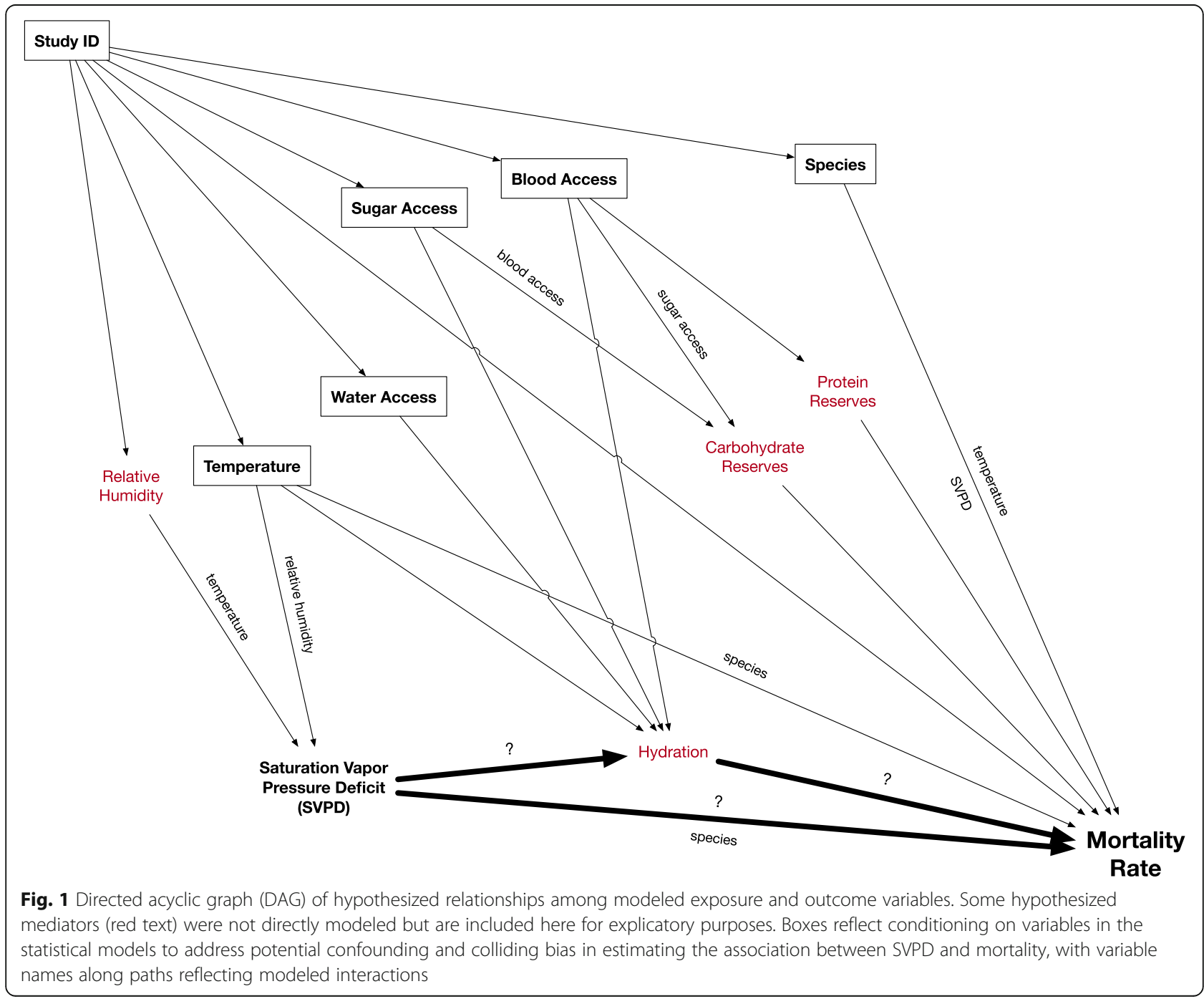


vapor pressure deficit (SVPD) was calculated from reported mean temperatures and relative humidities [75]. Saturation vapor pressure deficit is the difference between the actual vapor pressure in an air mass and the vapor pressure that would exist at saturation, which is non-linearly related to temperature. Depending on the format in which they were reported, survival data were extracted as (i) raw survival times for individual mosquitoes; (ii) mean or median longevities in days; or (iii) survival proportions at specified time points. Survival data were obtained from tables or via extraction from graphical survival curves or plots using GetData Graph Visualizer (v11.32521.0). Primary survival time data were requested via email from authors of most eligible studies published after 1995. To help assess possible climatic adaptations of Aedes populations used in each study reporting sufficient mosquito collection details, KöppenGeiger climate classifications [76] of geographical localities of origin were estimated using ArcMap 10.2.2.

\section{Survival time simulations}

All statistical analyses were conducted in R v3.3.1 [77]. We designed a simulation and pooled analysis approach which could flexibly harmonize disparate reporting formats among studies and model non-linear covariateoutcome relationships across the range of study conditions. Our strategy differs from a traditional metaanalysis in its use of simulated and reported data at the level of individual mosquitoes, rather than direct analysis of summary statistics or analytical results. For this reason, we refer to our study as a "pooled analysis" rather than a "meta-analysis". Individual mosquito survival times were simulated from reported survival curves or longevity summaries for each mosquito cohort for which raw observed survival times were unavailable. Simulations were performed with the $\mathrm{R}$ packages $n l s 2$ and Runuran [78, 79] under the Weibull and log-logistic distributions [80, 81]. Both models are commonly employed in survival analyses and accommodate agevarying mortality rates. The Weibull distribution has the property of proportional hazards, while the log-logistic is a proportional odds model [82].

Two-parameter Weibull and log-logistic cumulative distribution functions were fit via nonlinear least squares to observed survival curves for each experimental cohort that had a reported survival curve. A log-logistic or Weibull distribution was then selected with probability equal to the relative inverse residual sum of squares (RSS) of respective model fits for that cohort. Individual mosquito survival times were simulated using parameter estimates from the selected model. The number of simulated individual survival times for a cohort was equal to its reported sample size, and was distributed in proportion to the mortality events between each pair of reported observations (with rounding to the nearest integer). Simulated survival times were therefore internally calibrated by the reported survival proportions, with the fitted models guiding the distribution of survival times between observations. Right-censoring was modeled for experiments without complete follow-up, with censoring at the last observation time. Some cohorts required further simulation of additional survival times randomly drawn from the follow-up period, or random exclusion of excess individual times, to achieve the full sample size.

For cohorts with only a single censored survival observation or only a mean or median survival time, a Weibull or log-logistic model was randomly selected with probability equal to the relative inverse of summed RSS for all Weibull and log-logistic fitted models across experiments. Parameter values were drawn from prediction intervals of linear regression models relating estimated times of specified survival proportions to model scale or shape parameters among all fitted models. Survival proportions were either the proportion surviving at single censored observations, 0.5 for median survival times, or calculated survival proportions at mean survival times based on the properties of the Weibull and $\log$-logistic distributions [80, 81]. A total of 500 replicate simulation runs were performed.

\section{Cox regression analysis}

Simulated mosquito survival times were pooled across studies and analyzed using both stratified and mixed effects Cox regression models (rms and coxme R packages; $[83,84]$ ). The stratified model (with stratification by study) allows studies to differ in their baseline hazard functions but to contribute to the pooled estimation of hazard ratios for modeled covariates [85]. Here the hazard ratio represents the relative risk of death (over very short timeframes) for mosquitoes under two contrasting sets of conditions, for example at a given value of temperature and/or humidity $v s$ a reference value of temperature and/or humidity. The mixed effects model was identical to the stratified model but with the inclusion of study-level random effects instead of study-level stratification. We consider the stratified model to be the more appropriate analytical approach because it does not require an unrealistic assumption of identical baseline hazard functions across studies, but we included the mixed effects model as a check on the robustness of outputs from the stratified model.

The most appropriate humidity variable was determined via comparison of models containing relative humidity, vapor pressure or SVPD as covariates; SVPD yielded the model with the lowest Akaike information criterion (AIC) score and was selected for all remaining analyses. Covariates in the final models included temperature, SVPD, and water, sugar and blood 
provisioning. From a survival standpoint, sugar and blood meals were hypothesized to be partially redundant and were modeled with an interaction term. Temperature and SVPD were modeled with four-knot restricted cubic splines to accommodate possible nonlinear relationships with survival time. Separate regression models were fit for Ae. aegypti and Ae. albopictus. To compare survival times between species, an additional model was fit to the combined data from both species, with a binary indicator variable for species and separate temperature and SVPD splines for each species. Analyses were repeated for all 500 simulation replicates.

Pooled summary models were estimated by drawing ten random normally-distributed values for each model coefficient and simulation replicate using means and standard errors returned by individual stratified model fits; pooled means and confidence intervals were then calculated from the 5,000 accumulated random draws for each coefficient. Summary curves of hazard ratios were constructed in a similar fashion. Results from the Cox regression mixed effects model were summarized using the median and central $95 \%$ distribution of the 500 simulation replicates. Heterogeneity among studies was assessed by examining pooled study-level random effects from the mixed effects model.

\section{Sensitivity analyses}

In addition to comparisons between the stratified and mixed effects models, we assessed the robustness of the present study's statistical results via multiple sensitivity analyses. First, results of stratified Cox regression analyses for each study were individually evaluated to assess consistency with the results of the pooled analysis. Next, influences of individual studies on the pooled model were assessed by repeating stratified analyses after excluding each study in turn. As the log-logistic distribution does not meet the proportional hazards assumption underlying Cox regression, the full stratified dual-species analysis was repeated using data simulated only under the Weibull distribution.

\section{Results}

\section{Study selection and characteristics}

A flow diagram for study selection is presented in Additional file 1: Figure S1.1. A total of 1517 unique articles were screened on the basis of both titles and abstracts; 378 articles were assessed for eligibility via full-text review, and 17 studies met eligibility criteria for review. Table 1 summarizes characteristics of the selected studies, and Additional file 2: Table S2 provides further study details. Figure 2 illustrates the data simulation and analytical methodology subsequently used for these studies.
Selected studies collectively reported survival results from 192 unique mosquito cohorts (combining replicates), representing a total of about 15,547 adult female mosquitoes (8749 Ae. aegypti and 6798 Ae. albopictus). The selected studies as a group were broadly concerned with evaluating relationships between abiotic and biotic factors and mosquito life history parameters (summarized in Additional file 2: Table S2). Study populations had diverse geographical origins and included mosquito strains from temperate, wet tropical and seasonally-dry tropical climates; a single study [86] examined mosquitoes from a hot, arid climate. Only one study [87] examined caged mosquitoes exposed to ambient conditions rather than controlled laboratory conditions. Ten studies reported survival in Ae. aegypti alone, four studies focused on Ae. albopictus, and three studies reported results for both species. Two studies [88, 89] examined multiple strains of a single species. Most studies reported survival times via graphical survival curves, tables of proportions surviving at multiple time points, single censored observations, or mean or median survival times, though raw survival times were kindly provided by an author of one study [90], and Delatte et al. [30] reported plots of Weibull models fit to observed survival times.

Experimental conditions varied considerably among selected studies. Twelve studies conducted experiments under at least two different relative humidities; seven studies varied both temperature and relative humidity. The distribution of temperature and SVPD values utilized by the reviewed studies is summarized in Additional file 1: Figure S1.2. The range of temperature and humidity conditions used for survival experiments of Ae. aegypti were broader than for Ae. albopictus: 0.5$40{ }^{\circ} \mathrm{C}$ and $0-100 \% \mathrm{RH}$ (SVPD: $0.00-7.37 \mathrm{kPa}$ ) for $A e$. aegypti, but $15-35{ }^{\circ} \mathrm{C}$ and $0-97 \%$ RH (SVPD: $0.13-5.62$ $\mathrm{kPa})$ for Ae. albopictus. Nutrition and hydration provisioning varied widely among studies.

\section{Qualitative review}

Results of individual studies are briefly reviewed here, with further details provided in Additional file 2: Table S2. As some studies varied only temperature or relative humidity across experiments, independent effects on mortality from changes in temperature and SVPD could not be isolated for these studies and discussion may therefore focus only on temperature or humidity.

\section{Aedes aegypti}

In an early set of experiments, Lewis [91] found that mean longevity in a stock population of Ae. aegypti decreased with increasing temperature (from $10-30{ }^{\circ} \mathrm{C}$ ) and with increasing SVPD, and was higher in fed than unfed mosquitoes. Beeuwkes et al. [87] compared adult mortality rates in field-collected Ae. aegypti from two 


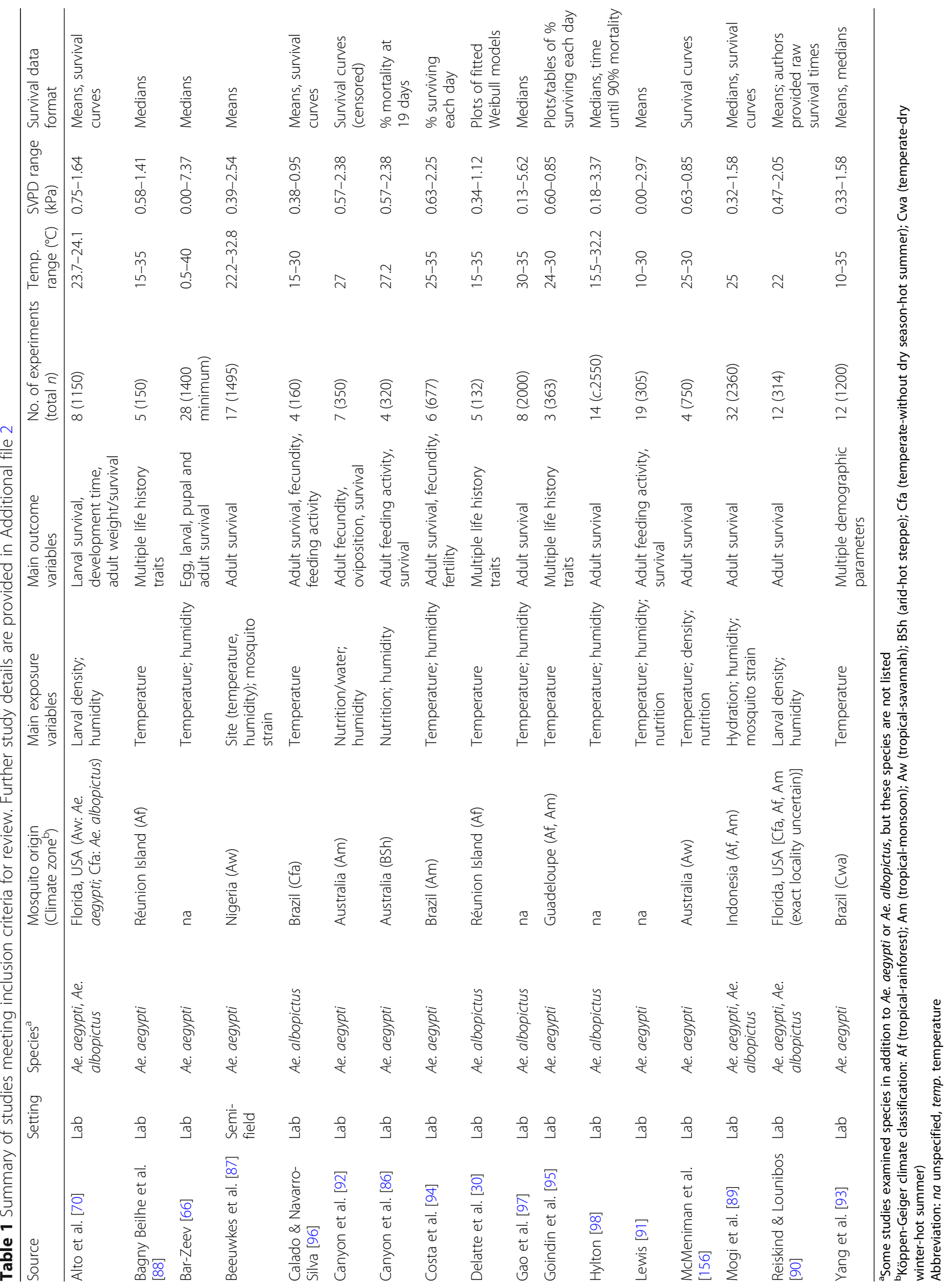




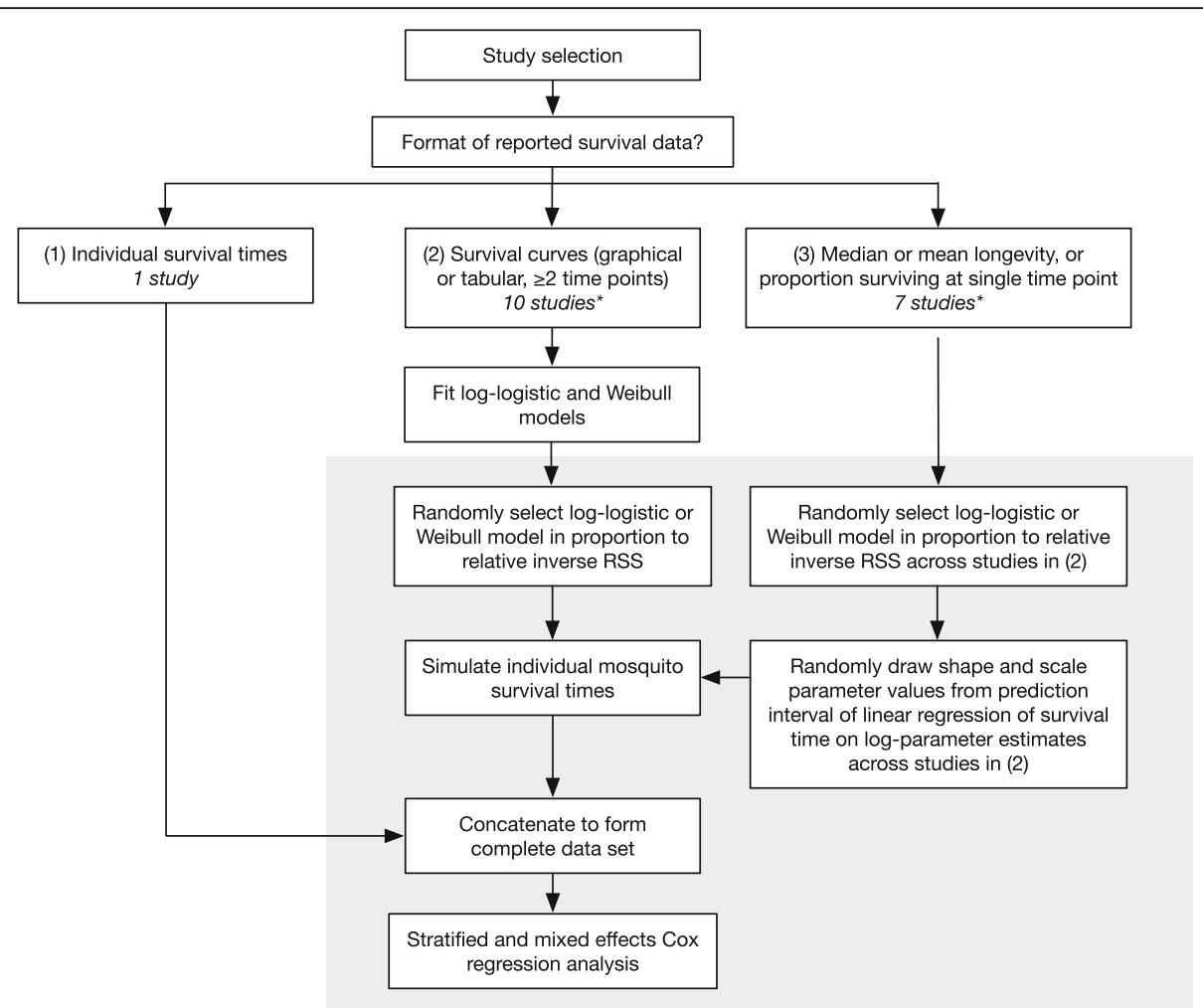

Fig. 2 Summary flow diagram of survival time simulations. Steps within the gray box were repeated to generate 500 simulated data sets, which were individually analyzed via stratified and mixed effects Cox regression prior to pooling. $\left(^{*}\right)$ One study reported some experiments as survival curves and some as median longevities

sites in Nigeria that were exposed to ambient conditions at both sites. The authors detected a site-by-season interaction on mortality (with lowest mortality at temperatures around $27{ }^{\circ} \mathrm{C}$ ) but suggested that temperature had a greater impact on survival than humidity. Bar-Zeev [66] examined mortality of $A e$. aegypti under forced starvation and desiccation at a broad range of temperatures and SVPDs and found complex nonlinear relationships among temperature, humidity and mortality. At most temperatures, longevity declined with decreasing humidity, but survival was similar across all humidities at $0.5^{\circ} \mathrm{C}$ and $40{ }^{\circ} \mathrm{C}$, suggesting a predominance of thermal effects other than desiccation at extreme temperatures.

Canyon et al. [92] found a reduction in longevity at low (34\%) vs high (84\%) relative humidities in an Australian population of Ae. aegypti from a wet tropical climate, while Canyon et al. [86] reported that longevity in an Australian Ae. aegypti population from a hot, dry climate depended on the presence or absence of water, sugar or blood sources, with survival similar or greater at low (34\%) than high (84\%) relative humidities. Yang et al. [93] reported that mortality of adult female $A e$. aegypti is lowest between about $15-30{ }^{\circ} \mathrm{C}$ and increases rapidly at temperatures below or above this range, and
Costa et al. [94] reported that longevity in Ae. aegypti decreased from $25{ }^{\circ} \mathrm{C}$ to $35{ }^{\circ} \mathrm{C}$ but was not significantly different at 60 vs $80 \%$ RH. Goindin et al. [95] found lowest mortality rates for Ae. aegypti from Guadeloupe at $27{ }^{\circ} \mathrm{C}$, but only tested a narrow range of temperatures $\left(24-30{ }^{\circ} \mathrm{C}\right)$ and did not systematically vary humidity. Bagny Beilhe et al. [88] reported that developmental rates, survival to adulthood, and adult longevity of $A e$. aegypti from Réunion were highly temperaturedependent, with greatest adult longevity at $25{ }^{\circ} \mathrm{C}$.

\section{Aedes albopictus}

Calado \& Navarro-Silva [96] reported that temperature affects adult longevity, fecundity and blood-feeding activity in a temperate-climate Ae. albopictus population from Brazil, with different optima for these life history parameters; adult female longevity was highest between $20-25{ }^{\circ} \mathrm{C}$. Gao et al. [97] found that the longevity of adult female Ae. albopictus decreases with decreasing humidity (from 97 to $0 \% \mathrm{RH}$ ) at $30{ }^{\circ} \mathrm{C}$ and $35{ }^{\circ} \mathrm{C}$. Hylton [98] reported that the longevity of adult female Ae. albopictus is affected by temperature and relative humidity, but that these relationships are complex. Within the range of conditions tested, higher temperature was generally associated with reduced longevity, but the 
relationship with humidity was less clear; at some temperatures, maximum longevity was achieved at intermediate humidities. Delatte et al. [30] found the lowest mortality rates for Ae. albopictus from Réunion at $15{ }^{\circ} \mathrm{C}$, with mortality increasing in a complex fashion at higher temperatures up to $35^{\circ} \mathrm{C}$.

\section{Combined studies}

Three studies examined both Ae. aegypti and Ae. albopictus, enabling direct species comparisons. Mogi et al. [89] reported that Ae. aegypti and Ae. albopictus strains from Indonesia varied in their desiccation tolerance, that urban strains were more desiccationtolerant than rural strains, and that Ae. aegypti survived longer than Ae. albopictus. Alto et al. [70] found significant effects and interactions of species, humidity and larval competition on adult longevity in Ae. aegypti and Ae. albopictus, with Ae. aegypti showing greater longevity than Ae. albopictus under most conditions; the direction and scale of the humidity effect on survival was not reported. Reiskind \& Lounibos [90] also examined the effect of larval competition on adult survival in both species, and reported greater longevity in Ae. aegypti relative to Ae. albopictus and reduced longevity in both species with reduced humidity (35 vs $85 \% \mathrm{RH}$ ).

\section{Additional studies}

Several additional studies that did not meet the strict criteria for inclusion in our review warrant mention and are described in Additional file 1.

Survival time simulation, study-level effects and model fit Among the 73 mosquito cohorts with sufficient reported survival data to fit Weibull or log-logistic models, 16 (22.0\%) were best fit by Weibull and 46 (63.0\%) by loglogistic models. Eleven cohorts (15.1\%) were fit equally well by either model, though these were each represented by observations at only three time points (enabling a perfect fit of either model). Across all 73 cohorts, log-logistic models achieved $59.6 \%$ of the weighting used to draw simulation models for the remaining cohorts.

Absolute time scales for mosquito mortality varied widely among studies, as illustrated in Fig. 3, which shows survival curves from three experiments as examples of outputs from the simulation process. While much of the variation in longevities is attributable to differences in modeled experimental conditions, the high variance estimated for study-level random effects from the mixed effects Cox regression model (Additional file 1: Figure S1.3) indicates substantial unexplained variability in mortality hazards. Hazard ratios in this context reflect impacts on mortality risk due to study-specific attributes (e.g. experimental procedures or genetic differences
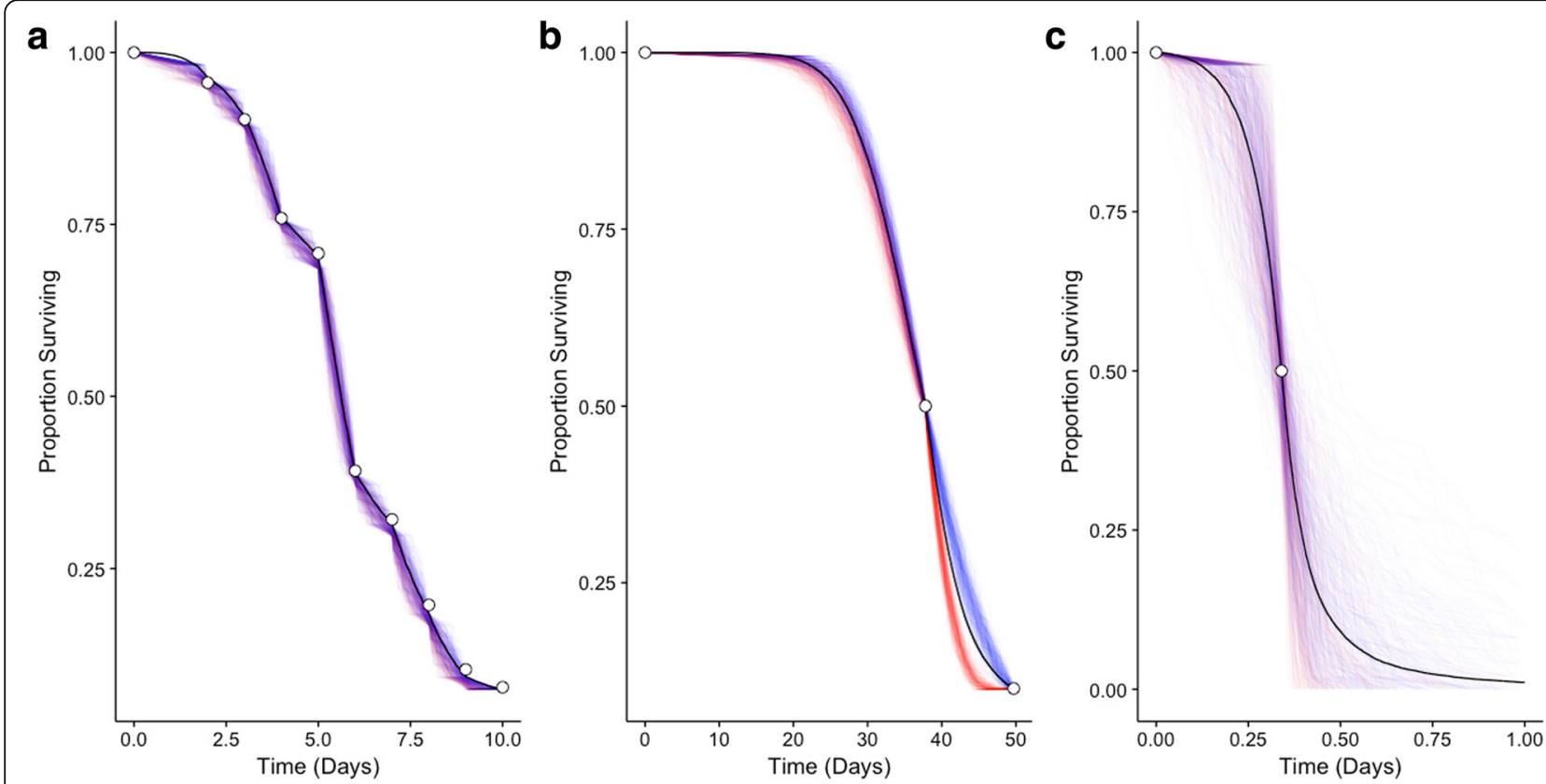

Fig. 3 Example simulated survival curves for individual experiments. a A right-censored experiment with reported survival observations at numerous time points (Aedes aegypti at $24.1^{\circ} \mathrm{C}$ and $75 \% \mathrm{RH}$, with water but no nutrition supplied; Alto et al. [70]). b A right-censored experiment with sparse reported survival observations (Ae. albopictus at $32.2^{\circ} \mathrm{C}$ and $60 \% \mathrm{RH}$, with sugar solution supplied; Hylton [98]). c An experiment with only median longevity reported (Ae. aegypti at $0.5^{\circ} \mathrm{C}$ and $85 \% \mathrm{RH}$, with no water or nutrition provided; Bar-Zeev [66]; $x$-axis has been truncated for display purposes). All 500 simulated data sets are shown for each experiment. Survival curves are colored according to their fitted model: Weibull (red), log-logistic (blue), or aggregate (black; all simulated data). Open circles indicate reported observations 
between mosquito populations) not captured by other model components. For example, mortality hazards in Bar-Zeev [66] were 12.2 (95\% CI: 7.2-20.7) times those predicted by modeled covariates alone, given their average effects across studies. While such large study effects merit further investigation, the use of a stratified Cox regression model for our primary analysis allowed us to accommodate unmodeled study-level differences without assuming a uniform baseline hazard across studies. Although mixed effects models are frequently employed to account for non-independence in pooled analyses, stratification requires fewer statistical assumptions.

Comparisons of relative fits for stratified Cox regression models containing differing sets of covariates, interactions, and functional forms of temperature and humidity are presented in Table 2. Mean differences in AIC values between models across all 500 simulated data sets supported the final model containing non-linear treatment of temperature, non-linear treatment of SVPD, differing temperature and humidity profiles for Ae. aegypti and Ae. albopictus, and inclusion of sugar, blood and water provisioning. The addition of species-specific non-linear terms for SVPD decreased model AIC values by an average of 2693.11 relative to a model with only temperature and water/nutrition, indicating that humidity significantly improves model fit. Substitution of SVPD with relative humidity or vapor pressure reduced model fit relative to SVPD but provided significant improvements over a model without any humidity term.

Table 2 Comparison of Cox regression model fits by mean change over 500 simulated data sets in Akaike Information Criterion (AIC) relative to a reference model of temperature alone (modeled linearly). All models were stratified by study

\begin{tabular}{ll}
\hline Model $^{a}$ & Mean AIC change \\
\hline temp & Ref. \\
temp + blood*sugar + water & -689.97 \\
temp*species + blood*sugar + water & -1328.38 \\
rcs(temp)*species + blood*sugar & -2991.04 \\
+ water & \\
rcs(temp)*species + SVPD*species & -4693.35 \\
+ blood*sugar + water & \\
rcs(temp)*species + rcs(SVPD)*species & -5684.15 \\
+ blood*sugar + water & \\
rcs(temp)*species + rcs(RH)*species & -5371.91 \\
+ blood*sugar + water & \\
rcs(temp)*species + rcs(VP)*species & -5043.55 \\
+ blood*sugar + water & \\
\hline
\end{tabular}

atemp, temperature $\left({ }^{\circ} \mathrm{C}\right)$; blood, access to blood meals provided; sugar, access to sugar sources provided; water, access to water provided; rcs, restricted cubic spline; SVPD, saturation vapor pressure deficit ( $\mathrm{kPa}$ ); $\mathrm{VP}$, vapor pressure $(\mathrm{kPa})$; $\mathrm{RH}$, relative humidity $(\%) .(*)$ indicates a modeled interaction. Spline knots were located at the default quantiles in rms $(0.05,0.35,0.65$, and 0.95 ; Harrell [155]) and correspond to the following values: 10.8, 25.0, 26.2, and $35.0^{\circ} \mathrm{C}$ for temperature, and approximately $0.13,0.63,1.11$, and $3.82 \mathrm{kPa}$ for SVPD (precise knot placements are provided in Additional file 3)

\section{Temperature, humidity and longevity}

As estimated species-specific hazard curves for temperature and SVPD were highly consistent between single- and dual-species Cox regression analyses, reporting of results focuses on the dual-species model as it allows direct comparison between Ae. aegypti and Ae. albopictus. The full specification of the pooled stratified model is presented in Additional file 3. Estimated temperature-related mortality profiles from the stratified model differed between Ae. aegypti and Ae. albopictus (Fig. 4a), with Ae. aegypti estimated to have a speciesspecific temperature optimum (i.e. lowest mortality hazard) at a higher temperature than Ae. albopictus $\left(27.5^{\circ} \mathrm{C}\right.$ vs $21.5^{\circ} \mathrm{C}$, respectively). Results suggest that Ae. albopictus may have a small survival advantage relative to $A$ e. aegypti between $15{ }^{\circ} \mathrm{C}$ (the lower bound of the available data for Ae. albopictus) and about $22{ }^{\circ} \mathrm{C}$, though the differences are not statistically significant. Aedes aegypti was estimated to have a significant survival advantage over Ae. albopictus above $22^{\circ} \mathrm{C}$, though possible convergence is evident around $35{ }^{\circ} \mathrm{C}$. For both species, mortality risk increases gradually as temperatures decrease from the species optima but rise rapidly with increasing temperature. Median estimates of temperature-related mortality hazards from the mixed effects model (Fig. 4c) were similar to the stratified model, but with substantially higher uncertainty (especially for Ae. albopictus), such that differences between species were not significant in this analysis.

Mortality profiles from the stratified model also differed between species for SVPD (Fig. 4b), with Ae. albopictus showing higher mortality than Ae. aegypti at all SVPD values modeled for Ae. albopictus (as with temperature, these estimates include the main effects for species). For both species, hazard ratios (HRs) increase rapidly from $0.0 \mathrm{kPa}$ to around $1.0 \mathrm{kPa}$, then increase more gradually as SVPD increases. The log HR curve for Ae. albopictus displays a marked temporary decrease between roughly $1.0 \mathrm{kPa}$ and $2.0 \mathrm{kPa}$, which may suggest overparameterization of the spline function or could reflect a true aspect of the vapor pressure-survival relationship for this species. Relative to the stratified model, the mixed effects model estimated a more rapid rise in mortality hazard for Ae. aegypti with increasing SVPD (Fig. 4d), less pronounced median differences between Ae. aegypti and Ae. albopictus, and much wider confidence intervals for both species. Differences in SVPDmortality profiles were not significant between species in the mixed effects model.

The combined effects of temperature and humidity on adult mortality are illustrated for the stratified model in Fig. 5 for RH terciles. For both species, the largest relative increase in mortality hazard occurs between 100\% $\mathrm{RH}$ (saturation) and 67\% RH at most temperatures. For 


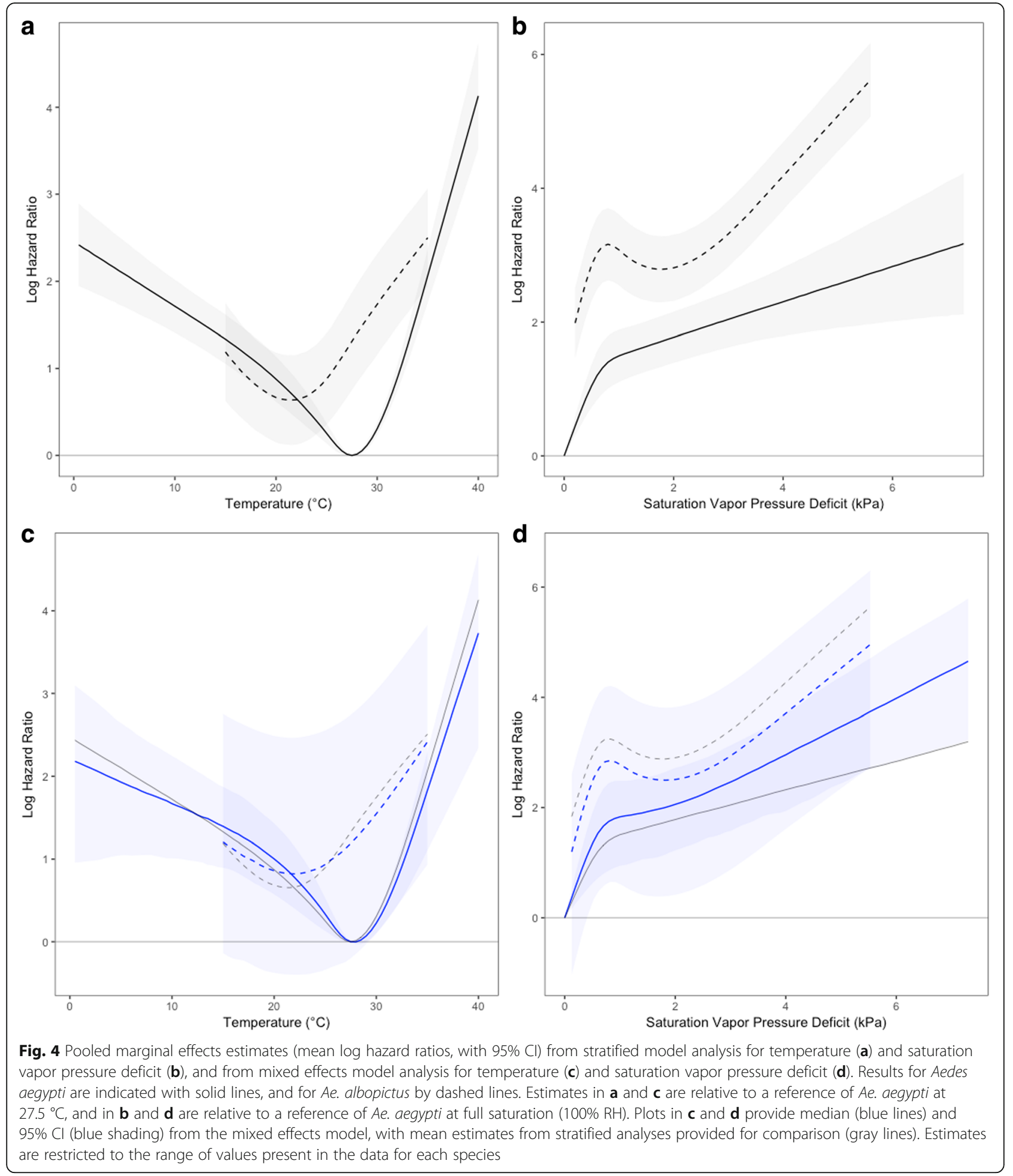

example, hazard ratio estimates for Ae aegypti at $27.5{ }^{\circ} \mathrm{C}$ are 4.76 (95\% CI: 3.26-6.97) at 67\% RH, 6.65 (95\% CI: 4. 48-9.86) at 33\% RH and 9.18 (95\% CI: 5.34-14.70) at $0 \%$ $\mathrm{RH}$, relative to saturation. The estimated influence of humidity (desiccation) on mortality hazards increases steadily for Ae aegypti with increasing temperature (Additional file 1: Figure S1.4), and similarly increases for Ae. albopictus above about $25{ }^{\circ} \mathrm{C}$. The main effect term for species revealed significantly higher mortality in $A e$. albopictus relative to Ae. aegypti in the stratified model 

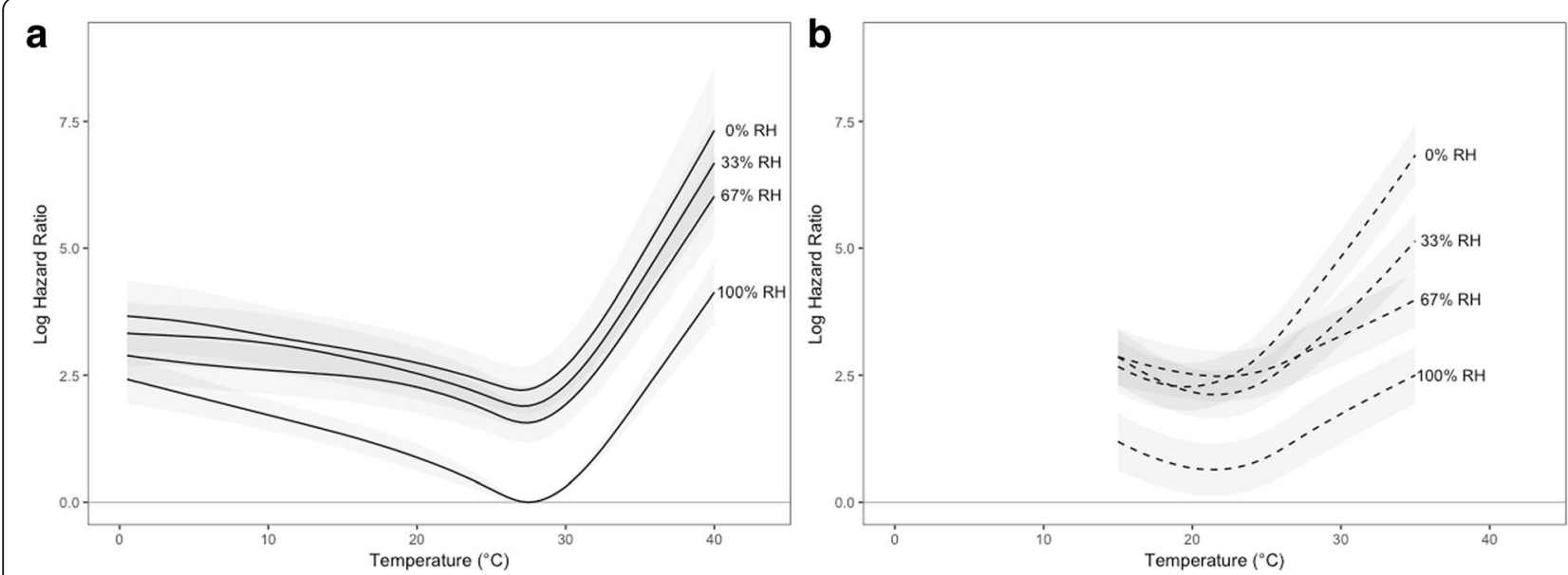

Fig. 5 Pooled joint effects estimates (mean log hazard ratios, with 95\% Cl) from stratified model analysis for temperature and select relative humidities (\%) for Aedes aegypti (a) and Ae. albopictus (b), illustrating the interacting effects of temperature and humidity. In order to facilitate direct comparisons between species, estimates for both species are relative to a reference of Ae. aegypti at $27.5^{\circ} \mathrm{C}$ and full saturation ( $\left.100 \% \mathrm{RH}\right)$

(HR: 4.01; 95\% CI: 1.15-14.01) but not in the mixed effects model (HR: 1.87; 95\% CI: 0.89-3.93). Pooled estimates for other covariates in the model revealed significant survival benefits from provisioning of water (stratified model: HR: 0.17; 95\% CI: 0.11-0.24; mixed effects model: HR: 0.20; $95 \%$ CI: $0.18-0.23$ ), sugar (stratified model: HR: 0.04; 95\% CI: 0.02-0.24; mixed effects model: HR: 0.06; 95\% CI: 0.04-0.11) and blood meals (stratified model: HR: 0.12; 95\% CI: 0.08-0.19; mixed effects model: HR: 0.18 ; 95\% CI: $0.12-0.25)$, but the simultaneous provisioning of sugar and blood did not improve survival relative to sugar alone (stratified model: HR for sugar-blood interaction: 8.94 [essentially the inverse of $\mathrm{HR}$ for blood meals]; 95\% CI: 5.47-14.59; mixed effects model: HR: 6.09; 95\% CI: 4.08-9.10; this result contrasts with that of Styer et al. [99]).

\section{Sensitivity analyses}

Stratified Cox regression analyses of simulated survival times for most individual studies were in approximate agreement with the pooled results (Additional file 4: Table S4.1, Figures S4.1-S4.4), but some studies yielded hazard curves that were inconsistent with the pooled analysis. For example, the Ae. aegypti temperature curve derived from Lewis [91] suggests a monotonically and linearly increasing mortality hazard between $10-30{ }^{\circ} \mathrm{C}$, and data from both Canyon et al. [86] and Reiskind \& Lounibos [90] suggest decreasing mortality for $A e$. aegypti with increasing SVPD. Data from a few studies [30, 93, 95] imply non-linear SVPD-mortality curves within narrow SVPD ranges. Results from Bar-Zeev [66] most closely matched the pooled SVPD hazard curve for Ae. aegypti, and the pooled model was generally robust to exclusion of this study except at temperature and SVPD extremes. Only Bar-Zeev's experiments included data at these extremes and model estimates in these ranges were reliant on these observations (Additional file 4: Figures S4.5-S4.6). It is notable that, although the results of the only semi-field study included in this review (Beeuwkes et al. [87]) are potentially influenced by highly variable field conditions and by inconsistent nutritional provisioning among experiments, results of that study are highly compatible with the pooled model, and the latter is robust to exclusion of the Beeuwkes data. Exclusion of other individual studies had minimal impact on the results of pooled analyses. Stratified analysis of survival data simulated entirely under the Weibull model yielded results similar to those from the combined Weibull/log-logistic models (Additional file 4: Figure S4.7).

A completed PRISMA checklist is provided in Additional file 5.

\section{Discussion}

To our knowledge, this study represents the first systematic review and pooled analysis of simultaneous associations of temperature and humidity with survival in adult female Ae. aegypti and Ae. albopictus. We identified 17 studies that reported experimental results with sufficient methodological detail and experimental scope to enable qualitative and quantitative assessments of these relationships. Reviewed studies collectively supported a temperature-dependent relationship between humidity and adult female survival in Ae aegypti and possibly Ae. albopictus, with the effect modified by factors including nutrition and hydration provisioning, larval competition, and probably genetics (i.e. population-level differences). Stratified survival analysis estimated the lowest relative mortality hazards for Ae. aegypti and Ae. albopictus around $27.5{ }^{\circ} \mathrm{C}$ and $21.5{ }^{\circ} \mathrm{C}$, respectively, with pronounced increases in mortality risk at lower and 
(especially) higher temperatures. Mortality was estimated to increase non-linearly with increasing desiccation stress in both species, corresponding with greater effects of aridity on mortality at higher temperatures. The incorporation of data from three studies $[70,89,90]$ that assessed survival for both Ae. aegypti and Ae. albopictus allowed direct estimation of relative species-specific mortality risks in our study, with other experimental factors controlled (see Additional file 4: Figure S4.8 for further discussion). Estimated adult mortality risks in the stratified analysis were higher for Ae. albopictus than for Ae. aegypti at all modeled vapor pressure deficits and at most modeled temperatures, though mortality hazards did not differ significantly between species in the mixed effects model. As relative measures, our model results can be directly used to modify survival functions in dynamic models, or to predict longevity in laboratory or field-based populations for which baseline survival trends have been measured.

The critical roles of temperature in Aedes population dynamics and associated disease transmission have been widely reported and frequently incorporated into statistical and mathematical models (e.g. [10, 11, 64, 65, 100]). Recently, Brady et al. [34] used generalized additive models (GAMs) to estimate the temperature-mortality relationship for adult Ae. aegypti and Ae. albopictus from field- and laboratory-based experiments. Their models estimated optimal temperatures for Ae. aegypti around $21{ }^{\circ} \mathrm{C}$ and for Ae. albopictus around $24.5{ }^{\circ} \mathrm{C}$ under controlled laboratory conditions, with an overall survival advantage for Ae. albopictus except at extreme high and low temperatures within the modeled $0-40{ }^{\circ} \mathrm{C}$ range. These results contrast with those from our stratified model, in which Ae. aegypti had its lowest mortality around $27.5{ }^{\circ} \mathrm{C}$, Ae. albopictus had optimum survival around $21.5{ }^{\circ} \mathrm{C}$, and Ae. aegypti had lower mortality risk than Ae. albopictus at most temperatures (although our model does not estimate mortality for Ae. albopictus across the full temperature range). The contradictory results between our study and those of Brady et al. [34] may reflect our inclusion of humidity as a modifier of the temperature-survival relationship, or differences in study selection and analytical approach. Model estimates of a lower temperature optimum for Ae. albopictus are consistent with the ecological niche models (e.g. [101, 102]) suggesting that the geographical range of Ae. albopictus extends to cooler climates than that of $A e$. aegypti. For example, Johnson et al. [102] used a MaxEnt model to relate USA county-level Ae. aegypti and Ae. albopictus presence to climatic variables independently of laboratory data, and estimated that the range of Ae. albopictus extends to cooler areas than Ae. aegypti can tolerate.
Both Ae. aegypti and Ae. albopictus are highly invasive vector species, and previous research has documented competitive interactions between these species at the larval stage, local replacement of Ae. aegypti by Ae. albopictus, and differences in their ecological niches (e.g. [101, 103-107]). These dynamics underscore the complexity of the environmental-mosquito interactions that influence species establishment and survival. The high uncertainty in mortality estimates for Ae. albopictus and the absence of statistically significant mortality differences between species in our mixed effects model caution against over-interpretation of species differences in our stratified model. However, consideration of the relationship between humidity and adult survival in both $A e$. aegypti and Ae. albopictus may provide future insights into the invasion and population ecology of both species, for example by refining ecological niche models and improving understanding of the role of urbanicity in enabling Aedes persistence in otherwise marginal environments (e.g. [101, 108, 109]). While our study specifically addresses the impact of temperature and humidity on adult longevity, relative mortality rates in these species are likely to be highly context-dependent, and the ability of either species to establish and thrive in a particular habitat further depends on other processes affecting adults as well as egg, larval and pupal stages $[10,20,30,31,33,40,67,70,91,92,96,104,110,111]$. Notably, laboratory experiments indicate that Ae. albopictus can outcompete Ae. aegypti when cohabitating in the immature stages (e.g. [112, 113]).

Compared with temperature, relatively little attention had previously been devoted to modeling the effect of humidity on adult survival in Aedes species. Focks et al. $[10,11]$, and derivative dynamic mosquito population models including Skeeter Buster [14, 65, 114, 115], modeled the relationship between adult survival and SVPD for Ae aegypti using a simple function that linearly reduces daily adult survival rates by $40 \%$ between 1.0 and $3.0 \mathrm{kPa}$ SVPD, with stable mortality rates below and above this range. Our results contrast with this model in estimating significant mortality increases between 0.0 and $1.0 \mathrm{kPa}$ and above $3.0 \mathrm{kPa}$, perhaps reflecting our study's flexible modeling strategy and inclusion of additional data sources. Surprisingly, our model estimated the most rapid increase in mortality risk for Ae aegypti between 0.0 and roughly $1.0 \mathrm{kPa}$ SVPD, with a generally slower increase in mortality above $1.0 \mathrm{kPa}$ SVPD. This unexpected result may reflect greater impacts on mortality from thermal processes other than desiccation at high temperatures. Lega et al. [64] also incorporated a simple humidity-dependent adult mortality function for $A e$. aegypti in the Dynamic Mosquito Simulation Model (DyMSiM; [15]). In their model, daily probability of adult survival is increased from 0.91 to 0.98 when $\mathrm{RH}$ is 
between $72 \%$ and $95 \%$ at temperatures from $4{ }^{\circ} \mathrm{C}$ to $41{ }^{\circ} \mathrm{C}$. The results of Lega et al. [64] demonstrated that the addition of a simple humidity-survival term can improve model fit to field data relative to temperature alone.

Mathematical Aedes models have frequently relied on temperature or humidity thresholds to set adult mortality rates, often at fixed levels or according to a linear step function (e.g. [10, 20]). Our results provide an opportunity to further refine these models by flexibly accounting for the non-linear and temperature-dependent relationship of humidity with adult survival. Because our equations are relative (i.e. expressed as hazard ratios), they have the flexibility to either augment or replace existing equations in dynamical models. Properly representing humidity effects in dynamical Aedes models is an increasingly important issue to address in a changing climate, as observed water vapor levels in the atmosphere have increased in recent decades [116] and are projected to keep increasing throughout this century as temperatures continue rising globally [117]. Yet, because of the relationship of humidity with temperature, the manner in which humidity is quantified is important. To explain, while overall vapor pressure (VP) generally increases under warming, relative humidity $(\mathrm{RH})$ generally remains about constant, and saturation vapor pressure deficit (SVPD) generally increases (i.e. desiccation potential rises) $[118,119]$. Therefore, an analysis of the impacts of humidity on Aedes survival under changing climatic conditions could potentially conclude that desiccation stress decreases, remains constant, or increases, depending on whether VP, RH, or SVPD is used as the humidity variable. In our analysis, SVPD provided a better model fit to survival data than either RH or VP. On its own, RH may be a poor metric of humidity for epidemiological models of infectious disease because it reflects an absolute measure of humidity only within the context of a given temperature [120]. By contrast, SVPD is a good proxy for desiccation stress because it correlates with evaporation rates and therefore measures the drying capacity of air [121]. For example, 25\% RH at $5{ }^{\circ} \mathrm{C}$ (SVPD: $0.65 \mathrm{kPa}$ ) represents a more similar desiccation environment to $75 \% \mathrm{RH}$ at $5{ }^{\circ} \mathrm{C}$ (SVPD: $0.22 \mathrm{kPa}$ ) than to $25 \% \mathrm{RH}$ at $40{ }^{\circ} \mathrm{C}$ (SVPD: $5.53 \mathrm{kPa}$ ).

While the sole use of experimental data in our study strengthens inferences of a causal effect of humidity on mortality, caution is warranted in making such interpretations given the presence of residual unexplained variation in mortality rates, as reflected by the large studylevel effects estimated by our mixed effects model. This variation is likely due to unmeasured or unreported factors affecting mosquito lifespan, including experimental conditions and/or species variants that we could not include in the model. In the laboratory setting these factors likely include genetics, diurnal temperature and humidity ranges, mating and oviposition activity, lightdark cycles, nutritional quality and frequency, intra- and interspecific larval competition, and adult density. Specific factors that could introduce uncertainty into the estimated humidity-longevity relationship include high variability of temperature and/or humidity within single experiments; inconsistent timing or quality of nutrition or hydration provisioning among experiments; provision of nutrition prior to the start of experiments; use of mosquitoes greater than one day post-eclosion for experiments; prevention of mating and oviposition; and use of stock colonies that had been maintained in captivity for many generations. These factors could not be reliably included in the statistical analyses due to inconsistent reporting across studies (summarized in Additional file 4: Table S4.1), but additional experimental and analytical attention would likely improve the precision and reliability of both relative and absolute survival estimates.

Our analysis was limited by the difficulty in modeling the large variation among studies in timing, quality and frequency of water and nutritional provisioning. We modeled these factors as simple binary presence/absence variables, and hence provide only a simple contrast between complete desiccation or starvation and availability of any hydration or nutrition sources posteclosion. However, blood meal source and quality have been shown to influence Aedes adult longevity [122, 123]; larval nutrition also impacts adult longevity in $A e$. aegypti and Ae. albopictus [70, 124] and influences their desiccation resistance [125]. Despite its demonstrated influence on adult longevity in laboratory experiments (e.g. $[86,126])$, sucrose-feeding may be a relatively insignificant source of nutrition for adult female Ae. aegypti in the field (e.g. [127]), and its impact on desiccation tolerance in field populations requires further study. More nuanced analyses of Aedes adult survival in relation to these and other nutrition-related variables may further improve population and disease modeling efforts.

The diverse geographical origins of Aedes populations in the reviewed studies imply significant collective genotypic and phylogenetic diversity among study populations, though the degree to which they represent the global diversity of Ae. aegypti and Ae. albopictus is unknown. Some studies performed experiments using stock colonies that had been in captivity for many generations, increasing the likelihood of adaptation to laboratory conditions in these strains and potentially reducing their desiccation tolerance relative to field populations. A majority of strains with reported collection localities hailed from regions with tropical climates, and only a single study used mosquitoes collected from a hot, arid locality [86]. Interestingly, the results from this latter study in arid Australia contrasted with results from the same author using a tropical population, with those from 
the tropical environment showing a greater impact of lower humidity on longevity, while those from an arid environment were robust when provisioned. Humidity is likely to be an important driver of mosquito dynamics in seasonally dry tropical environments, such as those with monsoon climates [76], to which Ae. albopictus has been hypothesized to have adapted prior to its global spread [128]. The poor representation of Aedes populations from arid and semi-arid regions is an important limitation of the present study. Studies assessing variation in desiccation tolerance among Aedes populations are scarce, and differences among strains used by studies in our review could not be completely isolated from potential confounders. Most laboratory studies investigating multiple conspecific populations of Ae aegypti or Ae. albopictus have found meaningful population-level variation in mortality rates $[87,89,110,129]$, though Machado-Allison \& Craig [130] only found significant differences between sylvan and urban lineages. Ecological and epidemiological Aedes models should aim to account for the unique genotypic and phenotypic profiles of mosquito populations of interest, which can display significant genetic isolation and differentiation even over relatively short distances [131-133]. Our analysis provides a baseline from which humidity effects on adult survival can be better incorporated into Aedes models, but careful studies of heat and desiccation tolerance in drylands Aedes populations would likely improve model accuracy in such regions.

Aedes aegypti distribution is variable across time and space and has been associated with small-scale habitat, climate and human demographic factors (e.g. [35, 104, 134, 135]). The existence of significant microclimatic variability in urban environments [58, 136-138], possible behavioral responses by mosquitoes to suboptimal conditions [86, 92, 139], and the modulating effect of humidity on adult Aedes behavior (e.g. [140]) further suggest that macroclimatic measurements may be unreliable proxies for conditions experienced by individual mosquitoes in the field. Even when ambient temperature and humidity are not conducive for survival, it may be possible for Aedes females to exploit gentler microhabitats. We hypothesize that compensatory behavioral responses to temperature and desiccation stress could loosen the tight linkage between environmental conditions and Aedes mortality estimated by laboratory experiments. Under this hypothesis, desiccation and temperature stresses may be most appropriately viewed as constraints on adult Aedes females, which could manifest as changes in survival, feeding, reproduction, or dispersal activities, depending on circumstances. Incorporation of the humidity-survival relationships estimated by the present study into dynamic mosquito models would represent an important step toward improving forecasts of Aedes-associated disease transmission in arid, semi-arid and seasonally dry regions. Further insights could emerge from modeling strategies that account for genotypic and phenotypic variation and evolution within Aedes populations (e.g. [141]), ecological heterogeneity and the effects of fluctuating environmental conditions, and local processes affecting mosquito physiology and behavior. Agent-based models are one such promising avenue of research [142-145].

Most studies included in the present review were performed in controlled laboratory environments. Relatively few studies have rigorously examined changing field conditions and adult longevity, making it difficult to assess how the findings from the laboratory studies might apply to natural mosquito populations. Short-term temperature fluctuations have important effects on life history traits and viral transmission in Ae. aegypti [111, 146-148] (reviewed for insects generally by Colinet et al. [149]). For example, laboratory experiments with $A e$. aegypti have demonstrated reduced immature development rates, adult female longevity, fecundity, and rates of infection by DENV at higher diurnal temperature ranges (DTRs) [111, 146]. The effects of fluctuating humidity may also have important effects on mortality, however these have not been extensively investigated. Lansdowne \& Hacker [110] examined the effect of naturally varying temperature and humidity regimes on adult Ae. aegypti survival and did not find significant differences relative to constant conditions, though the contribution of humidity in their study cannot be separated from thermal effects. Models of Aedes survival may benefit in the future from careful laboratory studies of Aedes mortality under fluctuating humidities and constant temperatures. In modeling the relationship between temperature and survival in Ae aegypti and Ae. albopictus, Brady et al. [34] included survival data from mark-release-recapture studies in order to quantify the substantial differences in mortality between laboratory and field populations. However, our review failed to identify fully field-based studies with sufficient humidity data for reliable inclusion in our model.

Differences in reported survival data formats presented a challenge to identifying uniform summary survival measures across studies. The wide range and varying overlap of experimental conditions among studies, and the hypothesized nonlinear relationships of temperature and humidity with longevity, further precluded the use of standard meta-analysis tools. Our approach enabled an integrated analysis of these disparate survival data, and accommodated non-linear effects of temperature and humidity, measured and unmeasured heterogeneity in study design, and age-dependent mortality, which has been detected for Aedes in both field and laboratory studies (e.g. [34, 149-152]). Survival time simulations 
represent a potential source of bias for experiments in which only a mean or median survival time was reported, as the shapes of their simulated survival curves may be biased toward those found in studies with fitted models. However, by simulating 500 data sets per experiment, with parameters drawn from the wide prediction intervals of the fitted models, we effectively increased model variance for low-reliability experiments and assigned greater weight to more reliable studies. Furthermore, as our stratified modeling strategy was designed to emphasize estimation of effects within studies, simulation of mosquito longevities is only likely to introduce significant bias if baseline hazards differ substantially among experiments within an individual study, for example when conditions are inconsistently variable.

Our simulations assumed Weibull or log-logistic distributions for survival times (other distributions are also reasonable, e.g. [34, 152-154]). Styer et al. [99] found that the logistic distribution provided the best fit for their large survival cohort of Ae. aegypti, though they did not evaluate the Weibull or log-logistic distributions. Brady et al. [34] reported that no single distribution best fit their survival data for Ae. aegypti and Ae. albopictus in all circumstances, but that the log-logistic and exponential distributions generally provided the best fits for Ae. aegypti and Ae. albopictus, respectively. We used the Weibull model (of which the exponential distribution is a special case) for its proportional hazards properties, and the log-logistic model because it provided comparable or better fit to our data. Bias is likely to be a concern only if true survival curves varied significantly in form among cohorts within a given study. Even in such cases, estimated hazard ratios can productively be interpreted as average effects over time, with nonproportionality indicating time-varying effects of covariates on mortality rates, or additional unmodeled factors influencing survival. These concerns can best be addressed through future studies examining raw (nonsimulated) survival times in Cox regression or accelerated failure time models [155].

The analytical results of this study were widely robust to exclusion of individual studies, and single-study analyses were generally, though not universally, consistent with the pooled results. Given the variable presence of unmodeled experimental factors or interactions that may modify the associations of temperature and humidity with survival, we should not expect a priori that all individual studies will conform precisely to the results of a simple pooled model. For example, Canyon et al. [86] found that Ae. aegypti females provided access only to water did not imbibe water when maintained at $84 \% \mathrm{RH}$ $\left(27.2^{\circ} \mathrm{C}\right.$ ) but did so at $34 \% \mathrm{RH}$, yielding faster mortality at the higher humidity; this result suggests the existence of an important interaction that was not included in our model and partially explains the discrepancy of the Canyon et al. [86] and pooled SVPD models. Some inconsistencies with the pooled model could result from the simpler forms of the single-study models, for example in studies where temperature and SVPD could not be modeled simultaneously or where too few conditions were examined to enable non-linear modeling. Other discrepancies may result from the finely-resolved spline models for some individual studies, which yield more complex SVPD-mortality curves than the pooled model, which was designed to yield a smooth hazard curve across a broad range of conditions. The causes of significant deviations from the pooled model warrant future investigation to identify other important factors affecting the relationships among temperature, humidity and survival. Despite the lack of universal concordance, a large proportion of single-study models were in basic agreement with the pooled model. In addition, the single-study hazard curves highlight the limited ranges of temperature and humidity examined by most studies, and demonstrate the utility of our analytical approach in combining overlapping curves to derive hazard estimates over a broader range. Statistical confidence in the stratified model was lowest at extreme temperatures and at high SVPD, reflecting a relative scarcity of experimental data and low reliability of simulations for most studies conducted under these conditions. It is vital that additional studies are conducted to fill these gaps given the growing importance of Aedes-borne viruses in arid environments. It is worth noting that, although the majority of evaluated studies did not meet our strict inclusion criteria, a great many studies reported experimental data that could inform aspects of Aedes survival beyond those on which we focused, or within other contexts or analytical frameworks.

Assessment of publication bias was not straightforward, but studies included in the review addressed a wide range of research questions, with just over half explicitly examining the association of humidity with survival. The high frequency of other primary research questions suggests a lower risk of publication bias in this body of work. A wide variety of search engines were used and no language or time restrictions were made on the search. While most of the databases we searched are biased toward publications in English, the inclusion of studies written in Mandarin and Portuguese (one study each) indicates that the search did not solely capture English-language publications. In addition, the geographical coverage of lead institutions indicates a fairly wide distribution of countries in the analysis.

Our analyses were limited by the availability of published literature reporting the associations among longevity, humidity and temperature. We identified gaps in the published literature that should be filled to improve 
our understanding of these dynamics. Few studies have examined Aedes mortality under arid conditions or at extreme temperatures, and relatively few studies have carefully examined the effect of humidity on Ae. albopictus mortality. Difficulties in accounting for microclimatic variations in temperature and humidity in field studies complicate the reliable estimation of relative humidityassociated mortality hazards in field $v s$ laboratory populations. Finally, experimental data for genetic variation in desiccation tolerance in Ae. aegypti and Ae. albopictus are scarce, preventing a detailed understanding of the evolutionary potential for adaptation to aridity within populations in marginal environments or in response to climatic change.

\section{Conclusions}

Our systematic review and pooled survival analysis revealed strong evidence for temperature-dependent and non-linear associations of humidity with adult female survival in Ae. aegypti and possibly Ae. albopictus, important vectors of major human pathogens including dengue, chikungunya, yellow fever and Zika viruses. Aedes aegypti was found to have greater longevity than Ae. albopictus at most temperatures and humidities and to have a higher optimum temperature, consistent with the current geographical distributions of these species. Our quantitative models may facilitate improved vector and disease forecasts across a range of spatial and temporal scales in arid, semi-arid, and seasonally dry environments. More robust modeling of mosquito responses to desiccation and temperature stress could also support projection of impacts from climate change and urbanization on the risks of Aedes-borne viral transmission.

\section{Additional files}

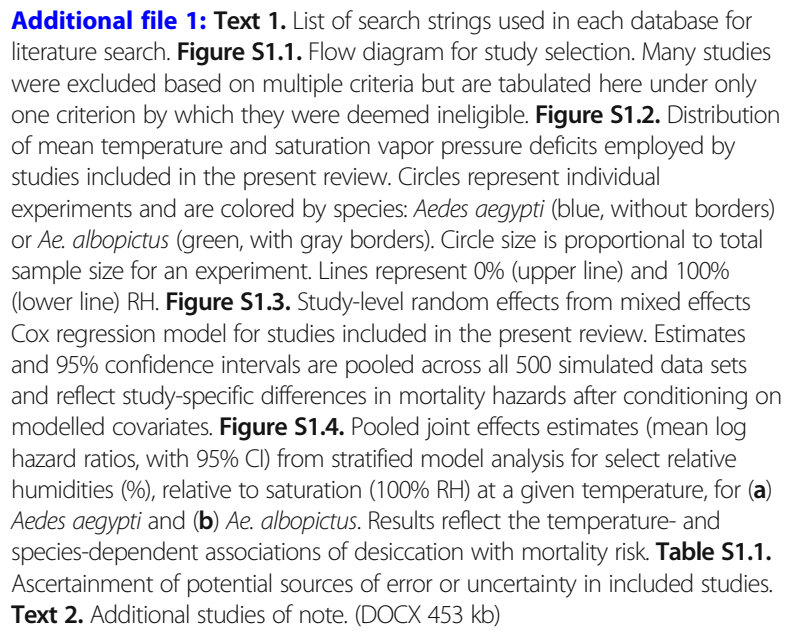

Additional file 2: Table S2. Summary of the methods, results and conclusions of the 17 studies included in the present review. (format: .xlsx) (XLSX $60 \mathrm{~kb}$ )

Additional file 3: Model specification of the full dual-species Cox regression model, with pooled coefficient estimates. (PDF $103 \mathrm{~kb}$ )

Additional file 4: Table S4.1. Single-study models used for sensitivity analyses assessing consistency of pooled model results with individual studies. Models represent the most complex treatment of variables in the pooled model possible for a given study. Figure S4.1. Comparison of model estimates for pooled (black) and single-study (blue) analyses of log hazard ratios (with $95 \% \mathrm{Cl}$ ) by temperature $\left({ }^{\circ} \mathrm{C}\right.$ ) for Aedes aegypti. Pooled model estimates are relative to a reference of Ae. aegypti at $27.5^{\circ} \mathrm{C}$. Figure S4.2. Comparison of model estimates for pooled (black) and single-study (blue) analyses of log hazard ratios (with 95\% Cl) by temperature $\left({ }^{\circ} \mathrm{C}\right)$ for Aedes albopictus. Figure S4.3. Comparison of model estimates for pooled (black) and single-study (blue) analyses of log hazard ratios (with $95 \% \mathrm{Cl}$ ) by saturation vapor pressure deficit $(\mathrm{kPa})$ for Aedes aegypti. Pooled model estimates are relative to a reference of Ae. aegypti at full saturation. Figure S4.4. Comparison of model estimates for pooled (black) and single-study (blue) analyses of log hazard ratios (with 95\% Cl) by saturation vapor pressure deficit $(\mathrm{kPa})$ for Aedes albopictus. Figure S4.5. Comparison of model estimates from all studies (black) and with individual studies excluded (blue) of log hazard ratios (with 95\% Cl) by temperature $\left({ }^{\circ} \mathrm{C}\right)$ for Aedes aegypti (solid lines) and Ae. albopictus (dashed lines). Model estimates are relative to a reference of Ae. aegypti at $27.5^{\circ} \mathrm{C}$. Figure S4.6. Comparison of model estimates from all studies (black) and with individual studies excluded (blue) of log hazard ratios (with 95\% Cl) by saturation vapor pressure deficit ( $\mathrm{kPa}$ ) for Aedes aegypti (solid lines) and Ae. albopictus (dashed lines). Figure S4.7. Comparison of model estimates after simulation under mixed Weibull and log-logistic survival time distributions (black, bold lines) and under the Weibull distribution alone (blue, thin lines) for (a) temperature and (b) saturation vapor pressure deficit. Estimates are shown for Aedes aegypti (solid lines) and Ae. albopictus (dashed lines), and are relative to a reference of $A$ e. aegypti at $27.5^{\circ} \mathrm{C}(\mathrm{A})$ or Ae. aegypti at full saturation (B). Text 1 . Relative mortality hazards between Ae. aegypti and Ae. albopictus. (DOCX 1290 kb)

Additional file 5: Completed PRISMA checklist. (DOC 64 kb)

\section{Abbreviations}

AIC: Akaike's information criterion; CHIKV: Chikungunya virus; DENV: Dengue virus; DTR: Diurnal temperature range; EIP: Extrinsic incubation period; KPa: Kilopascal; RH: Relative humidity; RSS: Residual sum of squares; SVPD: Saturation vapor pressure deficit; VP: Vapor pressure; YFV: Yellow fever virus; ZIKV: Zika virus

\section{Acknowledgements}

We thank Michael Reiskind for generously sharing raw data; Xianchun Li for kindly provided translation support; Jayleen Gunn for helpful advice on systematic reviews; Edward Bedrick, Paul Hsu and Brian Hallmark for useful discussions; and anonymous reviewers for their constructive feedback.

\section{Funding}

This study was funded with support from NIH/NIAID R01 Al091843-02 and National Aeronautics and Space Administration grant NNX16AO98G to KE and AM. The National Center for Atmospheric Research is sponsored by the National Science Foundation.

\section{Availability of data and materials}

The data supporting the conclusions of this article are included within the article and its additional files. The datasets developed and analysed during the current study are available from the corresponding author on reasonable request.

\section{Authors' contributions}

CS and KE designed the study. CS performed the literature searches, and CS, GC and KE reviewed the candidate articles. CS extracted the data, designed and performed the statistical analyses, interpreted the results, and wrote much of the manuscript. KE and AM contributed to interpreting the results and writing the manuscript. DW assisted with manuscript content and with 
summarizing reviewed articles. All authors read and approved the final manuscript.

\section{Competing interests}

The authors declare that they have no competing interests.

\section{Publisher's Note}

Springer Nature remains neutral with regard to jurisdictional claims in published maps and institutional affiliations.

\section{Author details}

'Department of Epidemiology and Biostatistics, Mel \& Enid Zuckerman College of Public Health, University of Arizona, 1295 N. Martin Ave, Tucson, AZ 85724, USA. ${ }^{2}$ National Center for Atmospheric Research, P.O. Box 3000 Boulder, CO 80307, USA. ${ }^{3}$ Department of Entomology, College of Agriculture \& Life Sciences, University of Arizona, P.O. Box 210036, Tucson, AZ 85721, USA.

Received: 21 July 2017 Accepted: 25 March 2018

Published online: 25 April 2018

\section{References}

1. Fauci AS, Morens DM. Zika virus in the Americas - Yet another arbovirus threat. N Engl J Med. 2016;374:601-4.

2. Lambrechts L, Scott TW, Gubler DJ. Consequences of the expanding global distribution of Aedes albopictus for dengue virus transmission. PLoS Negl Trop Dis. 2010;4:e646.

3. Bonizzoni M, Gasperi G, Chen X, James AA. The invasive mosquito species Aedes albopictus: current knowledge and future perspectives. Trends Parasitol. 2013;29:460-8.

4. Powell JR, Tabachnick WJ. History of domestication and spread of Aedes aegypti - a review. Mem Inst Oswaldo Cruz. 2013;108:11-7.

5. Messina JP, Brady OJ, Scott TW, Zou C, Pigott DM, Duda KA, et al. Global spread of dengue virus types: mapping the 70 year history. Trends Microbiol. 2014;22:138-46.

6. Bhatt $\mathrm{S}$, Gething PW, Brady OJ, Messina JP, Farlow AW, Moyes CL, et al. The global distribution and burden of dengue. Nature. 2013;496:504-7.

7. Weaver SC, Forrester NL. Chikungunya: evolutionary history and recent epidemic spread. Antivir Res. 2015;120:32-9.

8. Faria NR, Azevedo RDSDS, Kraemer MUG, Souza R, Cunha MS, Hill SC, et al. Zika virus in the Americas: early epidemiological and genetic findings. Science. 2016;352(6283):345-9.

9. Paules $\mathrm{Cl}$, Fauci AS. Yellow fever - once again on the radar screen in the Americas. N Engl J Med. 2017;376:1397-9.

10. Focks DA, Haile DG, Daniels E, Mount GA. Dynamic life table model for Aedes aegypti (L.) (Diptera, Culicidae) - analysis of the literature and model development. J Med Entomol. 1993;30:1003-17.

11. Focks DA, Haile DG, Daniels E, Mount GA. Dynamic life table model for Aedes aegypti (L.) (Diptera, Culicidae) - simulation results and validation. J Med Entomol. 1993;30:1018-28.

12. Otero M, Schweigmann N, Solari HG. A stochastic spatial dynamical model for Aedes aegypti. Bull Math Biol. 2008;70:1297-325.

13. Otero M, Solari HG, Schweigmann N. A stochastic population dynamics model for Aedes aegypti: formulation and application to a city with temperate climate. Bull Math Biol. 2006:68:1945-74.

14. Magori K, Legros M, Puente ME, Focks DA, Scott TW, Lloyd AL, Gould F. Skeeter Buster: a stochastic, spatially explicit modeling tool for studying Aedes aegypti population replacement and population suppression strategies. PLoS Negl Trop Dis. 2009:3:e508.

15. Morin CW, Comrie AC. Modeled response of the West Nile virus vector Culex quinquefasciatus to changing climate using the dynamic mosquito simulation model. Int J Biometeorol. 2010;54:517-29.

16. Andraud M, Hens N, Marais C, Beutels P. Dynamic epidemiological models for dengue transmission: a systematic review of structural approaches. PLoS One. 2012;7:e49085.

17. Johansson MA, Powers AM, Pesik N, Cohen NJ, Staples JE. Nowcasting the spread of chikungunya virus in the Americas. PLoS One. 2014;9:e104915.

18. Simoy MI, Simoy MV, Canziani GA. The effect of temperature on the population dynamics of Aedes aegypti. Ecol Model. 2015;314:100-10.

19. Dietz K. The estimation of the basic reproduction number for infectious diseases. Stat Meth Med Res. 1993;2:23-41.
20. Xu C, Legros M, Gould F, Lloyd AL. Understanding uncertainties in modelbased predictions of Aedes aegypti population dynamics. PLoS Negl Trop Dis. 2010;4:e830

21. Chan M, Johansson MA. The incubation periods of dengue viruses. PLoS One. 2012;7:e50972.

22. Tjaden NB, Thomas SM, Fischer D, Beierkuhnlein C. Extrinsic incubation period of dengue: knowledge, backlog, and applications of temperature dependence. PLoS Negl Trop Dis. 2013;7:e2207.

23. Macdonald $\mathrm{G}$. Theory of the eradication of malaria. Bull World Health Organ 1956;15:369-87.

24. Kramer LD, Ciota AT. Dissecting vectorial capacity for mosquito-borne viruses. Curr Opin Virol. 2015;15:112-8.

25. Bar-Zeev M. The effect of temperature on the growth rate and survival of the immature stages of Aedes aegypti. Bull Entomol Res. 1958;49:157-63.

26. Rueda LM, Patel KJ, Axtell RC, Stinner RE. Temperature-dependent development and survival rates of Culex quinquefasciatus and Aedes aegypti (Diptera: Culicidae). J Med Entomol. 1990;27:892-8.

27. Tun-Lin W, Burkot TR, Kay BH. Effects of temperature and larval diet on development rates and survival of the dengue vector Aedes aegypti in north Queensland, Australia. Med Vet Entomol. 2000;14:31-7.

28. Alto BW, Juliano SA. Precipitation and temperature effects on populations of Aedes albopictus (Diptera: Culicidae): implications for range expansion. J Med Entomol. 2001;38:646-56.

29. Löwenberg-Neto P, Navarro-Silva MA. Development, longevity, gonotrophic cycle and oviposition of Aedes albopictus Skuse (Diptera: Culicidae) under cyclic temperatures. Neotrop Entomol. 2004;33:29-33.

30. Delatte $\mathrm{H}$, Gimonneau G, Triboire A, Fontenille D. Influence of temperature on immature development, survival, longevity, fecundity, and gonotrophic cycles of Aedes albopictus, vector of chikungunya and dengue in the Indian Ocean. J Med Entoml. 2009:46:33-41.

31. Eisen L, Monaghan AJ, Lozano-Fuentes S, Steinhoff DF, Hayden MH, Bieringer PE. The impact of temperature on the bionomics of Aedes (Stegomyia) aegypti, with special reference to the cool geographic range margins. J Med Entomol. 2014;51:496-516.

32. Mordecai EA, Cohen JM, Evans MV, Gudapati P, Johnson LR, Lippi CA, et al. Detecting the impact of temperature on transmission of Zika, dengue, and chikungunya using mechanistic models. PLoS Negl Trop Dis. 2017;11:e0005568.

33. Yang HM, Macoris M d L d G, Galvani KC, Andrighetti MTM. Follow-up estimation of Aedes aegypti entomological parameters and mathematical modellings. Biosystems. 2011;103:360-71.

34. Brady OJ, Johansson MA, Guerra CA, Bhatt S, Golding N, Pigott DM, et al. Modelling adult Aedes aegypti and Aedes albopictus survival at different temperatures in laboratory and field settings. Parasit Vectors. 2013;6:351.

35. Hayden MH, Uejio CK, Walker K, Ramberg F, Moreno R, Rosales C, et al. Microclimate and human factors in the divergent ecology of Aedes aegypti along the Arizona, US/Sonora, MX border. EcoHealth. 2010;7:64-77.

36. Gharbi M, Quenel P, Gustave J, Cassadou S, La Ruche G, Girdary L, Marrama $L$. Time series analysis of dengue incidence in Guadeloupe, French West Indies: forecasting models using climate variables as predictors. BMC Infect Dis. 2011;11:166.

37. Descloux $E$, Mangeas M, Menkes CE, Lengaigne M, Leroy $A$, Tehei $T$, et al. Climate-based models for understanding and forecasting dengue epidemics. PLoS Negl Trop Dis. 2012;6:e1470.

38. Khormi HM, Kumar L, Elzahrany RA. Regression model for predicting adult female Aedes aegypti based on meteorological variables: a case study of Jeddah, Saudi Arabia. J Earth Sci Clim Ch. 2013;5:168.

39. Simões $T C$, Codeço $C T$, Nobre AA, Eiras AE. Modeling the non-stationary climate dependent temporal dynamics of Aedes aegypti. PLoS One. 2013;8:e64773.

40. Waldock J, Chandra NL, Lelieveld J, Proestos Y, Michael E, Christophides G, Parham PE. The role of environmental variables on Aedes albopictus biology and chikungunya epidemiology. Pathog Glob Health. 2013;107:224-41.

41. Naish S, Dale P, Mackenzie JS, McBride J, Mengersen K, Tong S. Climate change and dengue: a critical and systematic review of quantitative modelling approaches. BMC Infect Dis. 2014;14:167.

42. Xu H-Y, Fu X, Lee LKH, Ma S, Goh KT, Wong J, et al. Statistical modeling reveals the effect of absolute humidity on dengue in Singapore. PLoS Negl Trop Dis. 2014;8:e2805.

43. Hales S, de Wet N, Maindonald J, Woodward A. Potential effect of population and climate changes on global distribution of dengue fever: an empirical model. Lancet. 2002;360(9336):830-4. 
44. Pinto $E$, Coelho M, Oliver L, Massad $E$. The influence of climate variables on dengue in Singapore. Int J Environ Health Res. 2011;21:415-26.

45. Ho BC, Chan KL, Chan YC. Aedes aegypti (L.) and Aedes albopictus (Skuse) in Singapore city: 3. Population fluctuations. Bull World Health Organ. 1971;44:635

46. Li CF, Lim TW, Han LL, Fang R. Rainfall, abundance of Aedes aegypti and dengue infection in Selangor, Malaysia. Southeast Asian J Trop Med Public Health. 1985;16:560-8.

47. Mogi M, Khamboonruang C, Choochote W, Suwanpanit P. Ovitrap surveys of dengue vector mosquitoes in Chiang Mai, northern Thailand: seasonal shifts in relative abundance of Aedes albopictus and Ae. aegypti. Med Vet Entomol. 1988;2:319-24.

48. Karim MN, Munshi SU, Anwar N, Alam MS. Climatic factors influencing dengue cases in Dhaka city: a model for dengue prediction. Indian J Med Res. 2012;136:32-9.

49. Moore CG, Cline BL, Ruiz-Tibén E, Lee D, Romney-Joseph H, Rivera-Correa E. Aedes aegypti in Puerto Rico: environmental determinants of larval abundance and relation to dengue virus transmission. Am J Trop Med Hyg. 1978;27:1225-31

50. Vezzani D, Velázquez SM, Schweigmann N. Seasonal pattern of abundance of Aedes aegypti (Diptera: Culicidae) in Buenos Aires city, Argentina. Mem Inst Oswaldo Cruz. 2004;99:351-6.

51. Lozano-Fuentes S, Welsh-Rodriguez C, Monaghan AJ, Steinhoff DF, Ochoa-Martinez C, Tapia-Santos B, et al. Intra-annual changes in abundance of Aedes (Stegomyia) aegypti and Aedes (Ochlerotatus) epactius (Diptera: Culicidae) in high-elevation communities in Mexico. J Med Entomol. 2014;51:742-51.

52. Monaghan AJ, Morin CW, Steinhoff DF, Wilhelmi O, Hayden M, Quattrochi DA, et al. On the seasonal occurrence and abundance of the Zika virus vector mosquito Aedes aegypti in the Contiguous United States. PLoS Curr. 2016;8 https:/doi. org/10.1371/currents.outbreaks.50dfc7f46798675fc63e7d7da563da76.

53. Moore CG. Predicting Aedes aegypti abundance from climatologic data. In: Lounibos LP, Rey JR, Frank JH, editors. Ecology of mosquitoes: Proceedings of a workshop. Vero Beach: Florida Medical Entomology Laboratory; 1985.

54. Beebe NW, Cooper RD, Mottram P, Sweeney AW. Australia's dengue risk driven by human adaptation to climate change. PLoS Negl Trop Dis. 2009;3:e429.

55. Higgins RW, Yao Y, Wang XL. Influence of the North American monsoon system on the US summer precipitation regime. J Clim. 1997;10:2600-22.

56. Wang PK. Physics and dynamics of clouds and precipitation. Cambridge: Cambridge University Press; 2013.

57. Adams DK, Comrie AC. The North American monsoon. Bull Am Met Soc. 1997;78:2197-213

58. Mayer $H$, Matzarakis A, Iziomon MG. Spatio-temporal variability of moisture conditions within the urban canopy layer. Theor Apply Climatol. 2003;76:165-79.

59. CGIAR. The world's dry areas. Consultative Group on International Agricultural Research. 2017. http://drylandsystems.cgiar.org/content/worldsdry-areas. Accessed 3 July 2017

60. Lucio PS, Degallier N, Servain J, Hannart A, Durand B, Souza RND, Ribeiro ZM. A case study of the influence of local weather on Aedes aegypti (L.) aging and mortality. J Vector Ecol. 2013;38:20-37.

61. Benoit JB, Lopez-Martinez G, Phillips ZP, Patrick KR, Denlinger DL. Heat shock proteins contribute to mosquito dehydration tolerance. J Insect Physiol. 2010;56:151-6.

62. Chown S, Nicolson S. Insect physiological ecology. New York: Oxford University Press; 2004.

63. Urbanski J, Benoit J, Michaud M, Denlinger D, Armbruster P. The molecular physiology of increased egg desiccation resistance during diapause in the invasive mosquito, Aedes albopictus. Proc R Soc Lond (Biol). 2010;277(1694):2683-92.

64. Lega J, Brown HE, Barrera R. Aedes aegypti (Diptera: Culicidae) abundance model improved with relative humidity and precipitation-driven egg hatching. J Med Entomol. 2017;54:1375-84.

65. Ellis AM, Garcia AJ, Focks DA, Morrison AC, Scott TW. Parameterization and sensitivity analysis of a complex simulation model for mosquito population dynamics, dengue transmission, and their control. Am J Trop Med Hyg. 2011;85:257-64

66. Bar-Zeev M. The effect of extreme temperatures on different stages of Aedes aegypti (L.). Bull Entomol Res. 1957;48:593-9.

67. Christophers S. Aedes aegypti (L.). The yellow fever mosquito: Its life history, bionomics and structure. London: Cambridge University Press; 1960.
68. Steinhoff DF, Monaghan AJ, Eisen L, Barlage MJ, Hopson TM, Tarakidzwa I, et al. WHATCH'EM: A weather-driven energy balance model for determining water height and temperature in container habitats for Aedes aegypti. Earth Interact. 2016;20 https://doi.org/10.1175/El-D-15-0048.1.

69. Juliano SA, Stoffregen TL. Effects of habitat drying on size at and time to metamorphosis in the tree hole mosquito Aedes triseriatus. Oecologia. 1994;97:369-76.

70. Alto BW, Bettinardi DJ, Ortiz S. Interspecific larval competition differentially impacts adult survival in dengue vectors. J Med Entomol. 2015;52:163-70.

71. Bara J, Rapti Z, Cáceres CE, Muturi EJ. Effect of larval competition on extrinsic incubation period and vectorial capacity of Aedes albopictus for dengue virus. PLoS One. 2015;10:e0126703.

72. Maciel-de-Freitas R, Codeco CT, Lourenco-de-Oliveira R. Body size-associated survival and dispersal rates of Aedes aegypti in Rio de Janeiro. Med Vet Entomol. 2007:21:284-92.

73. Alto BW, Reiskind MH, Lounibos LP. Size alters susceptibility of vectors to dengue virus infection and dissemination. Am J Trop Med Hyg. 2008;79:688-95.

74. Liberati A, Altman DG, Tetzlaff J, Mulrow C, Gøtzsche PC, loannidis JPA, et al. The PRISMA statement for reporting systematic reviews and meta-analyses of studies that evaluate health care interventions: explanation and elaboration. PLoS Med. 2009;6:e1000100.

75. Murray FW. On the computation of saturation vapor pressure. J Appl Meteorol Climatol. 1967;6:203-4.

76. Peel MC, Finlayson BL, McMahon TA. Updated world map of the KöppenGeiger climate classification. Hydrol Earth Syst Sci. 2007;11:1633-44.

77. R Development Core Team. R: A language and environment for statistical computing. Vienna: R Foundation for Statistical Computing; 2016. https://www.R-project.org/

78. Grothendieck G. nls2. Non-linear regression with brute force. R package version 0.2. 2013. https://CRAN.R-project.org/package $=\mathrm{nls2}$.

79. Leydold J, Hörmann W. Runuran. R interface to the UNU.RAN random variate generators. $R$ package version 0.23.0. 2015. https://CRAN.R-project. org/package=Runuran

80. Johnson NL, Kotz S, Balakrishnan N. Continuous univariate distributions, vol. 1. 2nd ed. New York: Wiley; 1994.

81. Ashkar F, Mahdi S. Fitting the log-logistic distribution by generalized moments. J Hydrol. 2006;328:694-703.

82. Hosmer DW, Lemeshow S, May S. Applied survival analysis. 2nd ed. New York: Wiley; 2008.

83. Harrell FE. Rms: Regression Modeling Strategies 4.5-0. R package version 4.50. 2016. https://cran.r-project.org/web/packages/rms/index.html

84. Therneau TM. coxme: Mixed effects Cox models. R package version 2.2-5. 2015. https://cran.r-project.org/web/packages/coxme/index.html

85. Therneau TM, Grambsch PM. Modeling survival data: Extending the Cox model. New York: Springer; 2000.

86. Canyon D, Muller R, Hii JLK. Aedes aegypti disregard humidity-related conditions with adequate nutrition. Trop Biomed. 2013:30:1-8.

87. Beeuwkes H, Kerr JA, Weathersbee AA, Taylor AW. Observations on the bionomics and comparative prevalence of the vectors of yellow fever and other domestic mosquitoes of West Africa, and the epidemiological significance of seasonal variations. Trans R Soc Trop Med Hyg. 1933;26:425-47.

88. Bagny Beilhe L, Delatte H, Juliano SA, Fontenille D, Quilici S. Ecological interactions in Aedes species on Reunion Island. Med Vet Entomol. 2013;27:387-97.

89. Mogi M, Miyagi I, Abadi K, Syafruddin. Inter- and intra-specific variation in resistance to desiccation by adult Aedes (Stegomyia) spp. (Diptera: Culicidae) from Indonesia. J Med Entomol. 1996;33:53-7.

90. Reiskind $\mathrm{MH}$, Lounibos LP. Effects of intraspecific larval competition on adult longevity in the mosquitoes Aedes aegypti and Aedes albopictus. Med Vet Entomol. 2009:23:62-8

91. Lewis DJ. Observations on Aedes aegypti, L. (Dipt. Culic.) under controlled atmospheric conditions. Bull Entomol Res. 1933;24:363-72.

92. Canyon D, Hii JLK, Muller R. Adaptation of Aedes aegypti (Diptera: Culicidae) oviposition behavior in response to humidity and diet. J Insect Physiol. 1999:45:959-64

93. Yang HM, Macoris M d L d G, Galvani KC, Andrighetti MT, Wanderley DM. Assessing the effects of temperature on the population of Aedes aegypti, the vector of dengue. Epidemiol Infect. 2009;137:1188-202.

94. Costa EAPA, Santos EMM, Correia JC, Albuquerque CMR. Impact of smal variations in temperature and humidity on the reproductive activity and survival of Aedes aegypti (Diptera, Culicidae). Rev Brasil Entomol. 2010; 54:488-93. 
95. Goindin D, Delannay C, Ramdini C, Gustave J, Fouque F. Parity and longevity of Aedes aegypti according to temperatures in controlled conditions and consequences on dengue transmission risks. PLoS One. 2015;10:e0135489.

96. Calado DC, Navarro-Silva MA. Influence of temperature on longevity, fecundity, and hematophagic activity of Aedes (Stegomyia) albopictus Skuse, 1894 (Diptera, Culicidae) under laboratory condition. Rev Brasi Entomol. 2002;46:93-8.

97. Gao JZ, Zhen ZY, Xue JM, Huang PY, Zhao JP, Cao NH. Studies on the longevity of adult Aedes (S.) albopictus (Skuse) - the longevity of caged females under laboratory conditions. Acta Ento Sinica. 1984;27:182-8.

98. Hylton AR. Studies on longevity of adult Eretmapodites chrysogaster, Aedes togoi and Aedes (Stegomyia) albopictus females (Diptera: Culicidae). J Med Entomol. 1969;6:147-9.

99. Styer LM, Minnick SL, Sun AK, Scott TW. Mortality and reproductive dynamics of Aedes aegypti (Diptera: Culicidae) fed human blood. Vector Borne Zoonotic Dis. 2007;7:86-98.

100. Morin CW, Comrie AC, Ernst K. Climate and dengue transmission: evidence and implications. Environ Health Perspect. 2013;121:1264-72.

101. Kraemer MUG, Sinka ME, Duda KA, Mylne A, Shearer FM, Barker CM, et al. The global distribution of the arbovirus vectors Aedes aegypti and Ae. albopictus. eLife. 2015;4:e08347.

102. Johnson $T L$, Ubydul H, Monaghan AJ, Eisen L, Hahn MB, Hayden MH, et al. Modeling the environmental suitability for Aedes (Stegomyia) aegypti and Aedes (Stegomyia) albopictus (Diptera: Culicidae) in the contiguous United States. J Med Entomol. 2017;54:1605-14.

103. Benedict MQ, Levine RS, Hawley WA, Lounibos LP. Spread of the tiger: Global risk of invasion by the mosquito Aedes albopictus. Vector Borne Zoonotic Dis. 2007;7:76-85.

104. Lounibos LP, O'Meara GF, Juliano SA, Nishimura N, Escher RL, Reiskind MH, et al. Differential survivorship of invasive mosquito species in South Florida cemeteries: do site-specific microclimates explain patterns of coexistence and exclusion? Ann Entomol Soc Am. 2010;103:757-70

105. Lounibos LP, Bargielowski I, Carrasquilla MC, Nishimura N. Coexistence of Aedes aegypti and Aedes albopictus (Diptera: Culicidae) in peninsular Florida two decades after competitive displacements. J Med Entomol. 2016;53:1385-90.

106. Brady OJ, Golding N, Pigott DM, Kraemer MUG, Messina JP, Reiner RC, Scott TW, Smith DL, Gething PW, Hay SI. Global temperature constraints on Aedes aegypti and Ae. albopictus persistence and competence for dengue virus transmission. Parasit Vectors. 2014;7:338.

107. Yee DA. What can larval ecology tell us about the success of Aedes albopictus (Diptera: Culicidae) within the United States. J Med Entomol. 2016;53:1002-12.

108. Medley KA. Niche shifts during the global invasion of the Asian tiger mosquito, Aedes albopictus Skuse (Culicidae), revealed by reciprocal distribution models. Glob Ecol Biogeogr. 2010;19:122-33.

109. Mogi M, Armbruster PA, Tuno N, Aranda C, Yong HS. The climate range expansion of Aedes albopictus (Diptera: Culicidae) in Asia inferred from the distribution of Albopictus subgroup species of Aedes (Stegomyia). J Med Entomol. 2017:54:1615-25.

110. Lansdowne C, Hacker CS. The effect of fluctuating temperature and humidity on the adult life table characteristics of five strains of Aedes aegypti. J Med Entomol. 1975;11:723-33.

111. Carrington LB, Seifert SN, Willits NH, Lambrechts L, Scott TW. Large diurnal temperature fluctuations negatively influence Aedes aegypti (Diptera: Culicidae) life-history traits. J Med Entomol. 2013;50:43-51.

112. Juliano SA, Lounibos LP, O'Meara GF. A field test for competitive effects of Aedes albopictus on A. aegypti in South Florida: differences between sites of coexistence and exclusion? Oecologia. 2004;139:583-93.

113. Camara DCP, Codeço CT, Juliano SA, Lounibos LP, Riback TIS, Pereira GR, et al. Seasonal differences in density but similar competitive impact of Aedes albopictus (Skuse) on Aedes aegypti (L.) in Rio de Janeiro, Brazil. PLoS One. 2016; 11:e0157120

114. Hopp MJ, Foley JA. Global-scale relationships between climate and the dengue fever vector, Aedes aegypti. Clim Chang. 2001;48:441-63.

115. Wesolowski A, Qureshi T, Boni MF, Sundsøy PR, Johansson MA, Rasheed SB, et al. Impact of human mobility on the emergence of dengue epidemics in Pakistan. Proc Natl Acad Sci USA. 2015;112:11887-92.

116. Wang J, Dai A, Mears C. Global water vapor trend from 1988 to 2011 and its diurnal asymmetry based on GPS, radiosonde, and microwave satellite measurements. J Clim. 2016;29:5205-22.

117. Stocker T. Climate change 2013: the physical science basis: Working Group I contribution to the Fifth assessment report of the Intergovernmental Panel on Climate Change. Cambridge: Cambridge University Press; 2014.
118. Trenberth KE, Fasullo J, Smith L. Trends and variability in column-integrated atmospheric water vapor. Climate Dyn. 2005;24:741-58.

119. Monaghan AJ, Moore SM, Sampson KM, Beard CB, Eisen RJ. Climate change influences on the annual onset of Lyme disease in the United States. Ticks Tick Borne Dis. 2015;6:615-22.

120. Davis RE, McGregor GR, Enfield KB. Humidity: a review and primer on atmospheric moisture and human health. Environ Res. 2016;144:106-16.

121. Anderson DB. Relative humidity or vapor pressure deficit. Ecology. 1936;17:277-82.

122. Harrington LC, Edman JD, Scott TW. Why do female Aedes aegypti (Diptera: Culicidae) feed preferentially and frequently on human blood? J Med Entomol. 2001;38:411-22.

123. Joy TK, Arik AJ, Corby-Harris V, Johnson AA, Riehle MA. The impact of larval and adult dietary restriction on lifespan, reproduction and growth in the mosquito Aedes aegypti. Exp Gerontol. 2010:45:685-90.

124. Klowden MJ, Chambers GM. Reproductive and metabolic differences between Aedes aegypti and Ae. albopictus (Diptera: Culicidae). J Med Entomol. 1992;29:467-71.

125. Sawabe K, Mogi M. Differences in energy metabolism and adult desiccation resistance among three Aedes (Stegomyia) species (Diptera: Culicidae) from South Sulawesi, Indonesia. J Med Entomol. 1999;36:101-7.

126. Briegel H, Knüsel I, Timmermann SE. Aedes aegypti: size, reserves, survival, and flight potential. J Vector Ecol. 2001;26:21-31.

127. Scott TW, Naksathit A, Day JF, Kittayapong P, Edman JD. A fitness advantage for Aedes aegypti and the viruses it transmits when females feed only on human blood. Am J Trop Med Hyg. 1997;57:235-9.

128. Mogi M, Armbruster P, Tuno N, Campos R, Eritja R. Simple indices provide insight to climate attributes delineating the geographic range of Aedes albopictus (Diptera: Culicidae) prior to worldwide invasion. J Med Entomol. 2015;52:647-57.

129. Crovello TJ, Hacker CS. Evolutionary strategies in life table characteristics among feral and urban strains of Aedes aegypti (L.). Evolution. 1972;26:185-96.

130. Machado-Allison CE, Craig GB. Geographic variation in resistance to desiccation in Aedes aegypti and A. atropalpus (Diptera: Culicidae). Ann Entomol Soc Am. 1972;65:542-7.

131. Merrill SA, Ramberg FB, Hagedorn HH. Phylogeography and population structure of Aedes aegypti in Arizona. Am J Trop Med Hyg. 2005;72:304-10.

132. Endersby NM, Hoffmann AA, White VL, Ritchie SA, Johnson PH, Weeks AR. Changes in the genetic structure of Aedes aegypti (Diptera: Culicidae) populations in Queensland, Australia, across two seasons: implications for potential mosquito releases. J Med Entomol. 2011;48:999-1007.

133. Urdaneta-Marquez L, Failloux A-B. Population genetic structure of Aedes aegypti, the principal vector of dengue viruses. Infect Genet Evol. 2011;11:253-61.

134. Walker KR, Joy TK, Ellers-Kirk C, Ramberg FB. Human and environmental factors affecting Aedes aegypti distribution in an arid urban environment. J Am Mosq Control Assoc. 2011:27:135-41.

135. Landau KI, van Leeuwen WJD. Fine scale spatial urban land cover factors associated with adult mosquito abundance and risk in Tucson, Arizona. J Vector Ecol. 2012;37:407-18.

136. Arnfield AJ. Two decades of urban climate research: a review of turbulence, exchanges of energy and water, and the urban heat island. Int J Climat. 2003; 23:1-26

137. LaDeau SL, Allan BF, Leisnham PT, Levy MZ. The ecological foundations of transmission potential and vector-borne disease in urban landscapes. Funct Ecol. 2015;29:889-901.

138. Wong PP-Y, Lai P-C, Low C-T, Chen S, Hart M. The impact of environmental and human factors on urban heat and microclimate variability. Build Environ. 2016:95:199-208.

139. Kessler S, Guerin PM. Responses of Anopheles gambiae, Anopheles stephensi, Aedes aegypti, and Culex pipiens mosquitoes (Diptera: Culicidae) to cool and humid refugium conditions. J Vector Ecol. 2008;33:145-9.

140. Haufe WO. Quantitative measurements of activity of Aedes aegypti (L.) (Culicidae: Diptera) in response to changes in the hygrothermal environment. Int J Biomet. 1964;7:245-64.

141. Kearney M, Porter WP, Williams C, Ritchie S, Hoffmann AA. Integrating biophysical models and evolutionary theory to predict climatic impacts on species' ranges: the dengue mosquito Aedes aegypti in Australia. Funct Ecol. 2009;23:528-38.

142. Isidoro C, Fachada N, Barata F, Rosa A. Agent-based model of Aedes aegypti population dynamics. In: Lopes LS, Lau N, Mariano P, Rocha LM, editors. Progress in Artificial Intelligence, Proceedings, vol. 5816. Berlin: Springer-Verlag Berlin; 2009. p. 53-64. 
143. de Almeida SJ, Martins Ferreira RP, Eiras AE, Obermayr RP, Geier M. Multiagent modeling and simulation of an Aedes aegypti mosquito population. Environ Model Softw. 2010;25:1490-507.

144. Dommar CJ, Lowe R, Robinson M, Rodo X. An agent-based model driven by tropical rainfall to understand the spatio-temporal heterogeneity of a chikungunya outbreak. Acta Trop. 2014;129:61-73.

145. Manore CA, Hickmann KS, Hyman JM, Foppa IM, Davis JK, Wesson DM, Mores CN. A network-patch methodology for adapting agent-based models for directly transmitted disease to mosquito-borne disease. J Biol Dyn. 2015;9:52-72.

146. Lambrechts L, Paaijmans KP, Fansiri T, Carrington LB, Kramer LD, Thomas $M B$, Scott TW. Impact of daily temperature fluctuations on dengue virus transmission by Aedes aegypti. Proc Natl Acad Sci USA. 2011;108:7460-5.

147. Carrington LB, Armijos MV, Lambrechts L, Barker CM, Scott TW. Effects of fluctuating daily temperatures at critical thermal extremes on Aedes aegypti life-history traits. PLoS One. 2013;8:e58824.

148. Carrington LB, Armijos MV, Lambrechts L, Scott TW. Fluctuations at a low mean temperature accelerate dengue virus transmission by Aedes aegypti. PLoS Negl Trop Dis. 2013;7:e2190.

149. Colinet $H$, Sinclair BJ, Vernon $P$, Renault $D$. Insects in fluctuating thermal environments. Annu Rev Entomol. 2015;60:123-40.

150. Harrington LC, Edman JD, Costero AC, Clark GG, Kittayapong P, Scott TW. Analysis of survival of young and old Aedes aegypti (Diptera: Culicidae) from Puerto Rico and Thailand. J Med Entomol. 2001;38:537-47.

151. Harrington LC, Vermeylen F, Jones JJ, Kitthawee S, Sithiprasasna R, Edman JD, Scott TW. Age-dependent survival of the dengue vector Aedes aegypti (Diptera: Culicidae) demonstrated by simultaneous release-recapture of different age cohorts. J Med Entomol. 2008;45:307-13.

152. Styer LM, Carey JR, Wang J-L, Scott TW. Mosquitoes do senesce: departure from the paradigm of constant mortality. Am J Trop Med Hyg. 2007;76:111-7.

153. Degallier N, Servain J, Lucio PS, Hannart A, Durand B, de Souza RN, Ribeiro ZM. The influence of local environment on the aging and mortality of Aedes aegypti (L.): case study in Fortaleza-CE, Brazil. J Vector Ecol. 2012;37:428-41.

154. Clements AN, Paterson GD. The analysis of mortality and survival rates in wild populations of mosquitoes. J Appl Ecol. 1981;18:373-99.

155. Harrell FE. Regression modeling strategies. Cham: Springer International Publishing; 2015

156. McMeniman CJ, Lane RV, Cass BN, Fong AWC, Sidhu M, Wang Y, O'Neill SL. Stable introduction of a life-shortening Wolbachia infection into the mosquito Aedes aegypti. Science. 2009;323:141-4.

\section{Submit your next manuscript to BioMed Central and we will help you at every step:}

- We accept pre-submission inquiries

- Our selector tool helps you to find the most relevant journal

- We provide round the clock customer support

- Convenient online submission

- Thorough peer review

- Inclusion in PubMed and all major indexing services

- Maximum visibility for your research

Submit your manuscript at www.biomedcentral.com/submit 